\title{
Issues of Protection of Personal Rights After the Death of the Victim in Civil Law
}

\author{
Mariam Dolidze \\ Master of law, Senior Specialist at City Hall Economy and Property Management Service \\ of Chkhorotsku Municipality
}

\section{ARTICLE INFO}

Article History:

Received 19.10.2021

Accepted 15.11.2021

Published 20.12.2021

Keywords:

Dead,

Personal Rights,

Protection

\section{ABSTRACT}

The protection of personal human rights is especially important after the death of the victim.

First of all, it is necessary to determine what is meant by the personal rights of a person, what personal rights can be protected after the death of the victim, in order to determine what is meant by the protection of the personal rights of the deceased. Then it is necessary to find out what the characteristics of a person are, by whom, how and in what form these rights are protected, and what harm can be caused by the violation of personal rights.

It is true that the violation of personal rights is not allowed by law, but, nevertheless, there are many facts around us when the personal rights of the deceased and the living are violated.

It is also desirable to protect personal rights acquired at birth from being violated by others both during the life and after the death of the victim. It is true that a person with personal rights protects his life and can claim compensation for property and / or non-property damage, but after the death of the victim, the law prohibits relatives or friends of the deceased from claiming compensation. for moral damage in violation of these rights. However, if a person was rehabilitated after his / her death, but the unlawful condemnation of the victim or other illegal legal actions damaged both the name and reputation of the heir, it is recommended to give the victim's heir the right to claim compensation for the damage directly caused to him. 


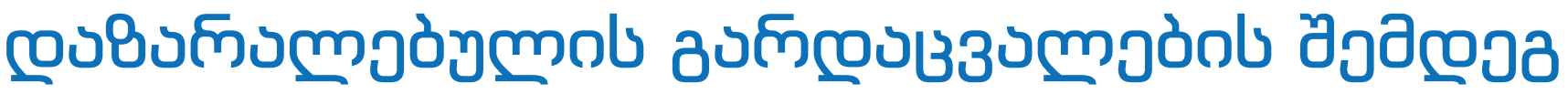

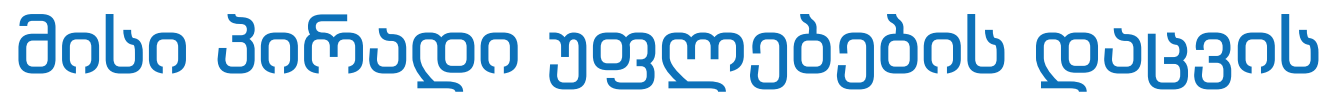

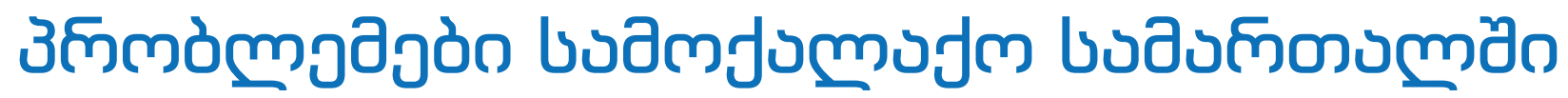

\author{
పงm̄oง ஹ̣mmodo

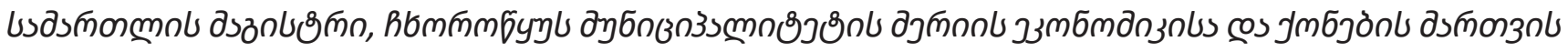

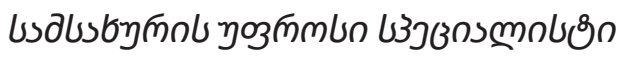

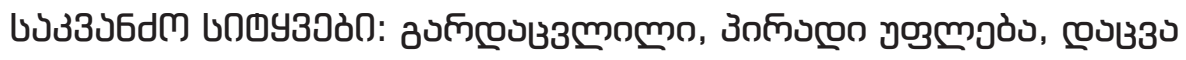

\section{วอง১3งณn}

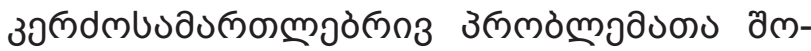

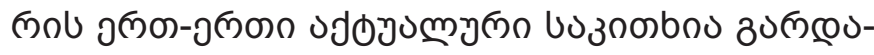

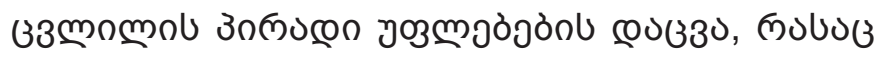

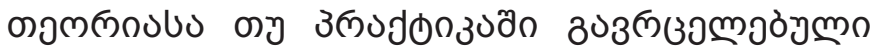

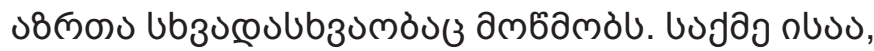

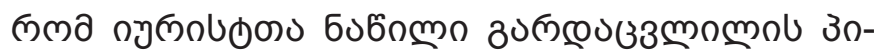

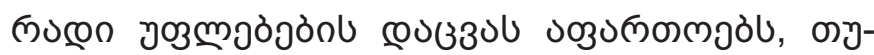

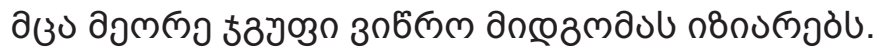

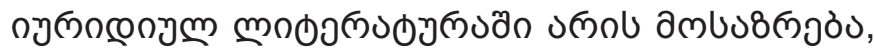

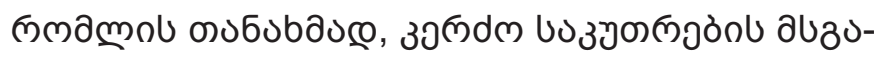

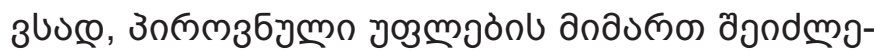

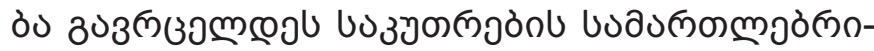

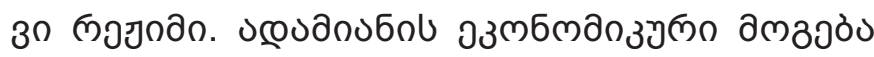

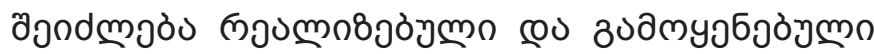

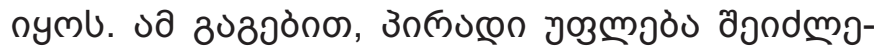

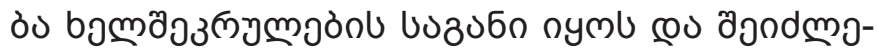

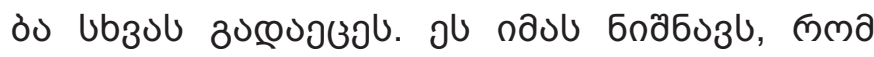

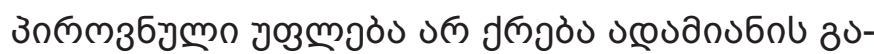

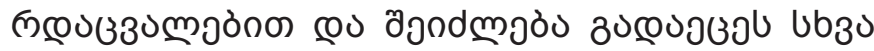

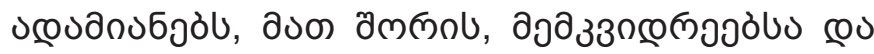

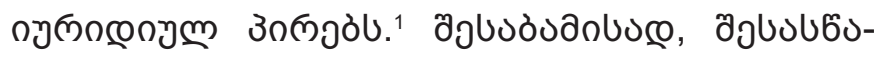

1 Hocks, A., 2012. The Right to Publicity After Death: Postmortem Personality Rights in Washington in the Wake of Experience Hendrix v. HendrixLicensing.com, Seattle University Law Review, Vol. 36, 280.

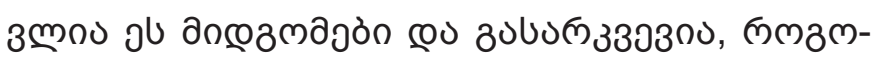

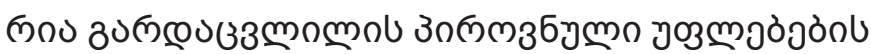

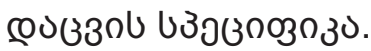

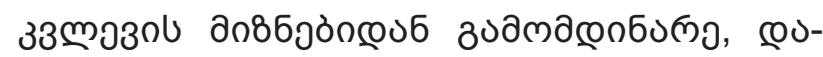

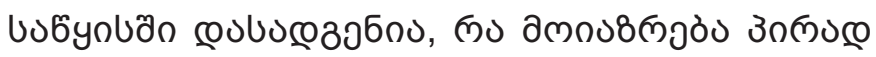

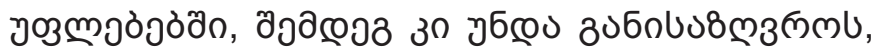

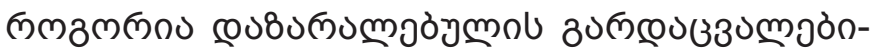

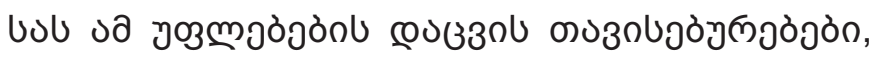

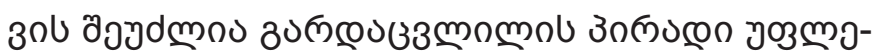

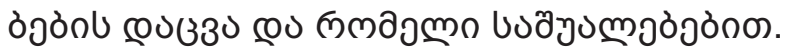

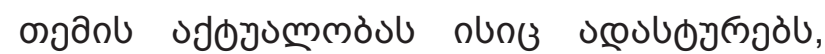

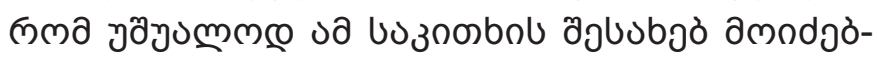

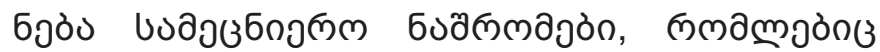

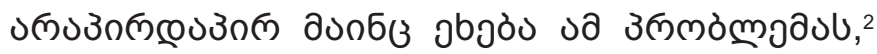

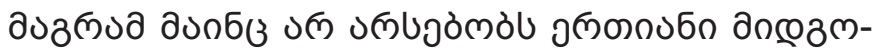

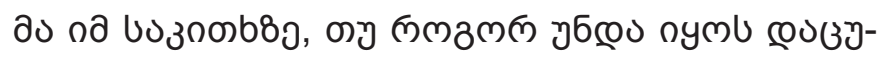

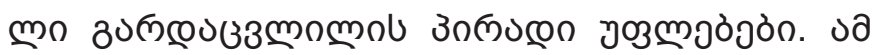

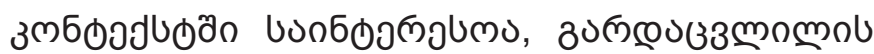

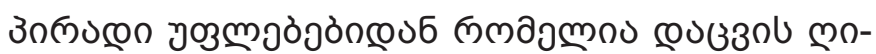

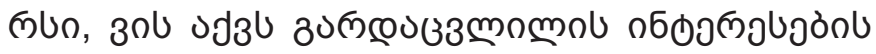

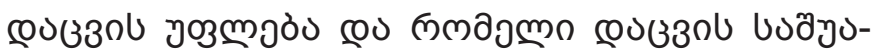

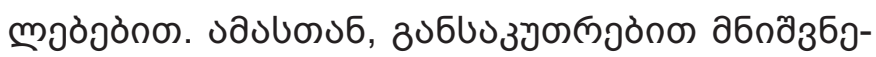

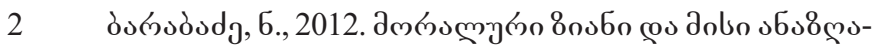

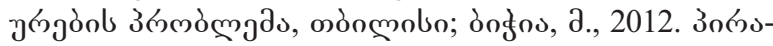

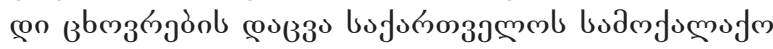

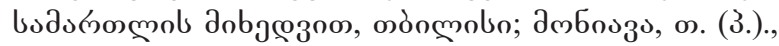

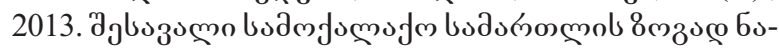

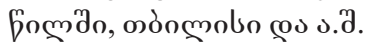




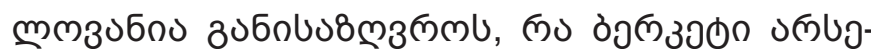

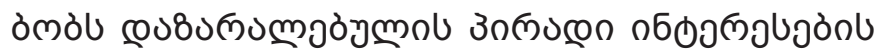

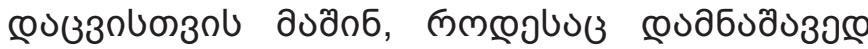

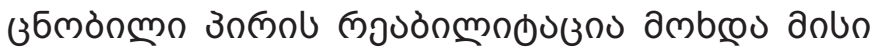

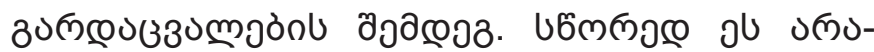

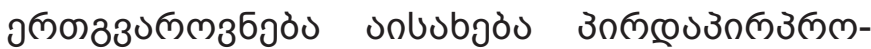

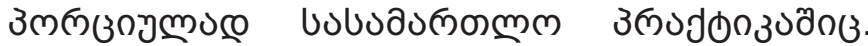

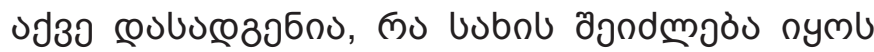

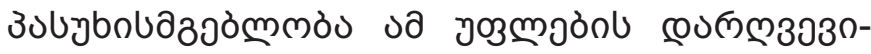

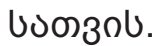

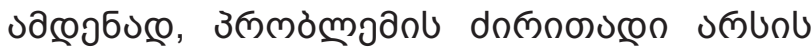

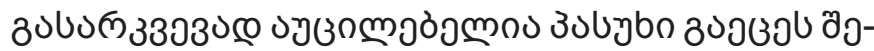

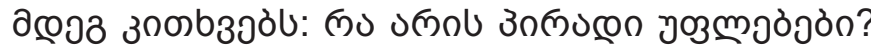

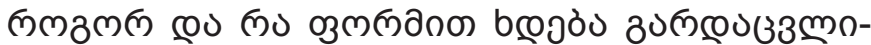

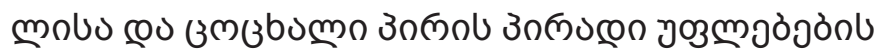

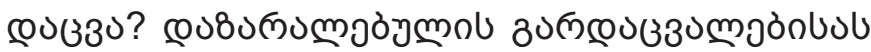

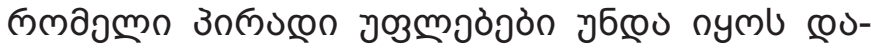

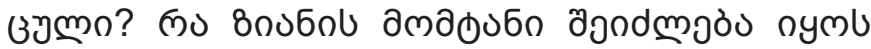

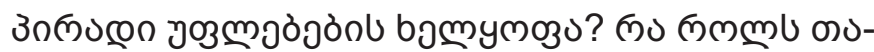

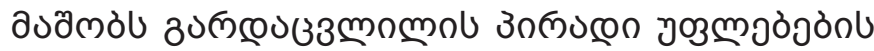

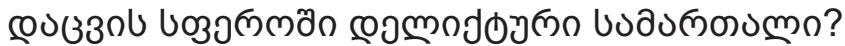

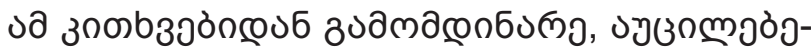

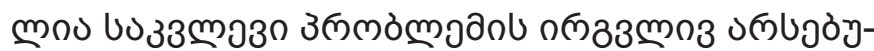

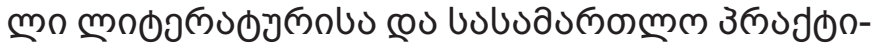

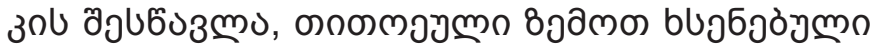

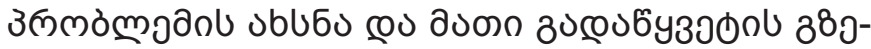
onb amdnoठ̀.

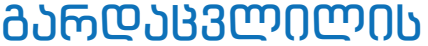

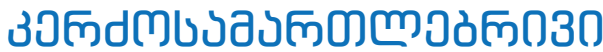

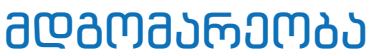

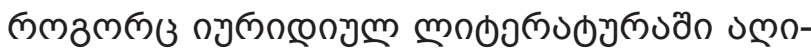

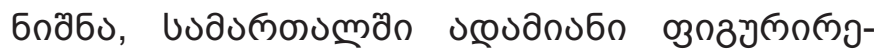

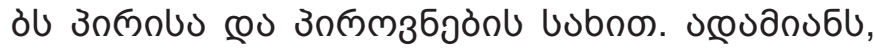

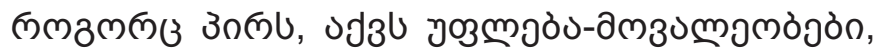

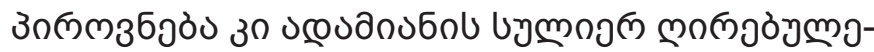

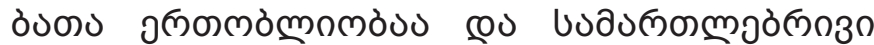

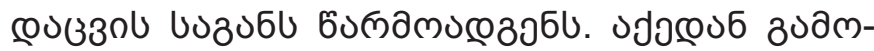

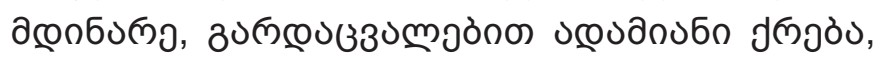

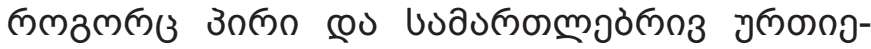

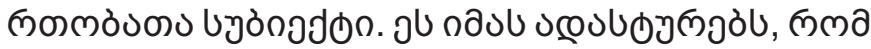

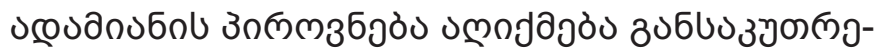

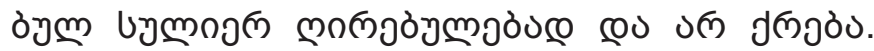
до

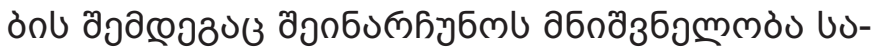

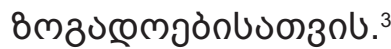

3

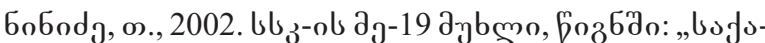

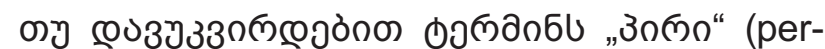

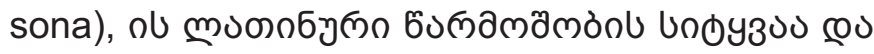

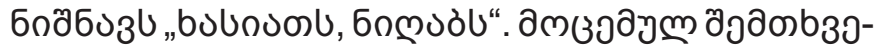

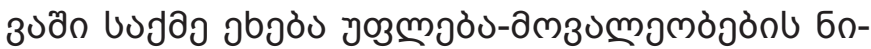

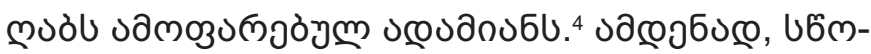

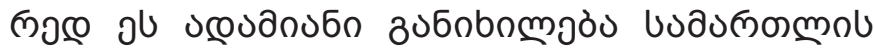

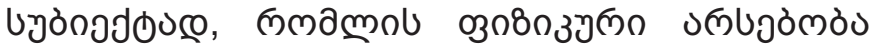
doun zuলnos

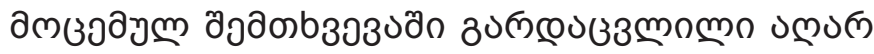

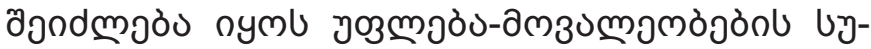

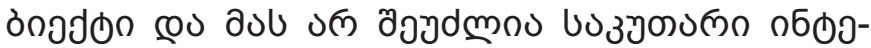

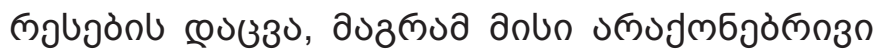

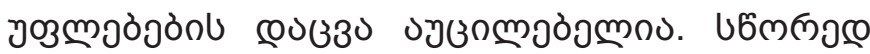

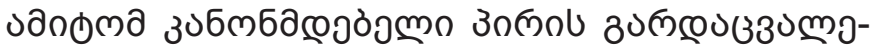

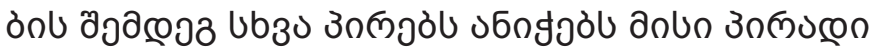

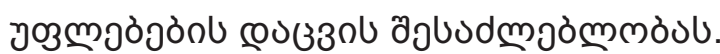

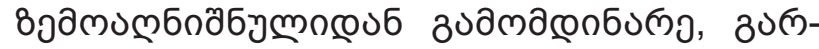

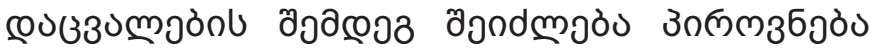

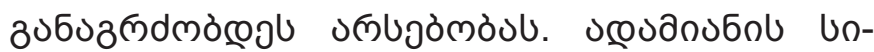

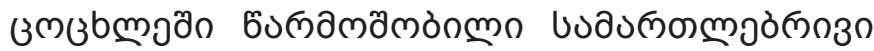

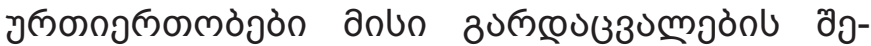

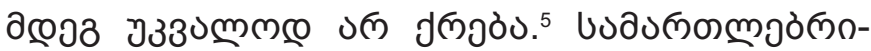

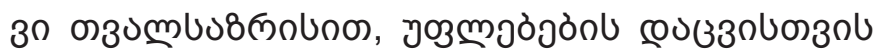

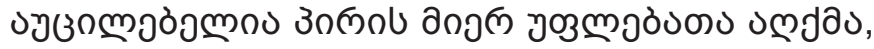

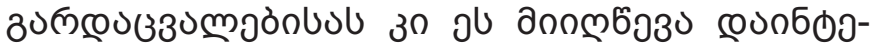

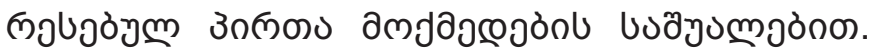

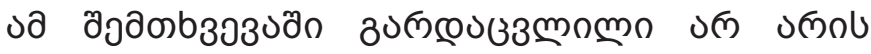

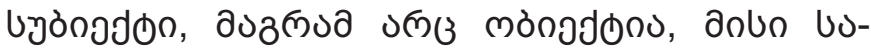

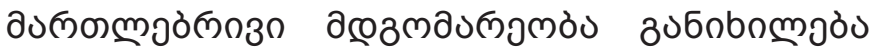

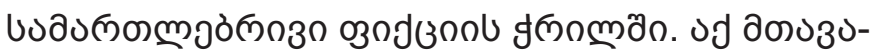

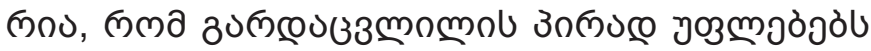

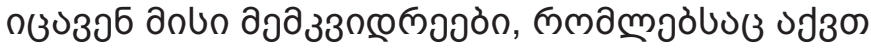

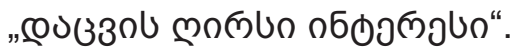

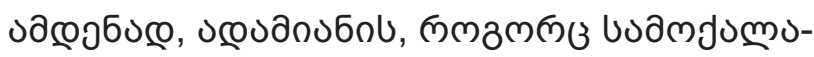

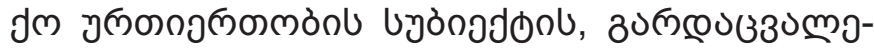

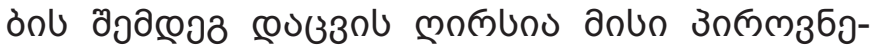

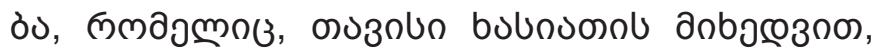

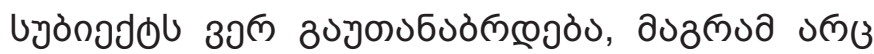

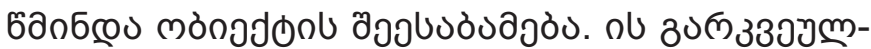

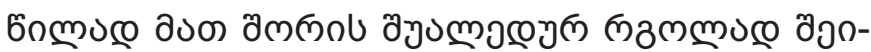

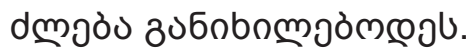

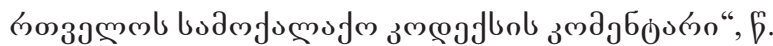
I, oòngobon, 33.79.

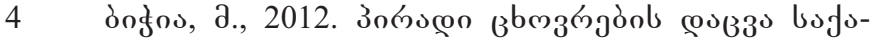

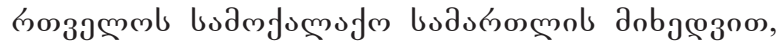
oònmobn, 33. 249-250.

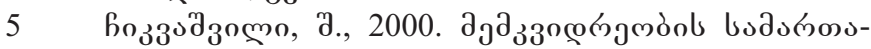
mo, oònģolın. 33.6 . 


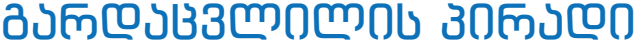

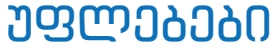

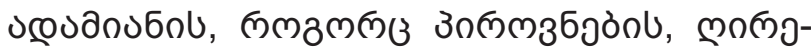

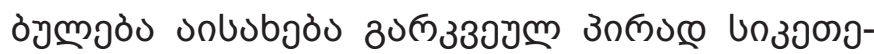

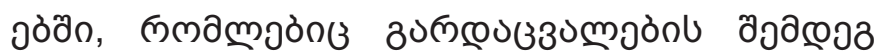

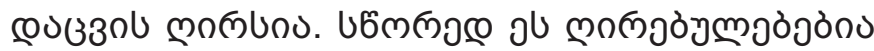

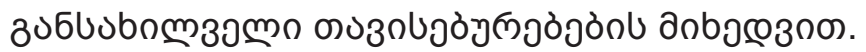

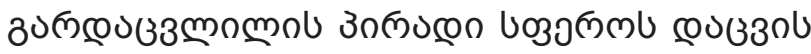

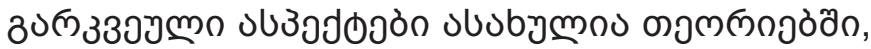

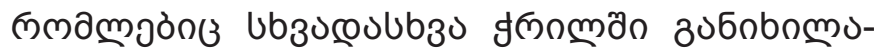

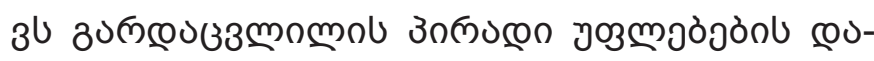

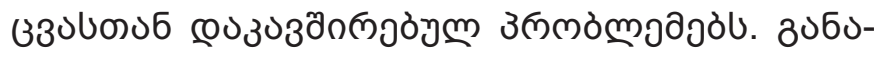

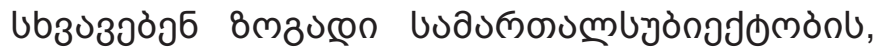

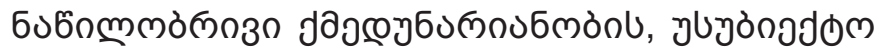

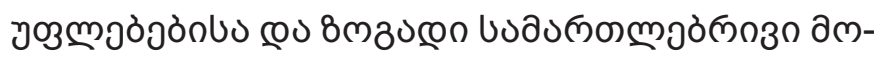

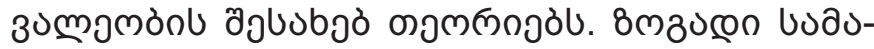

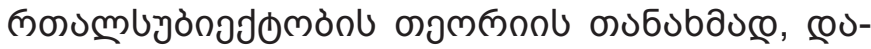

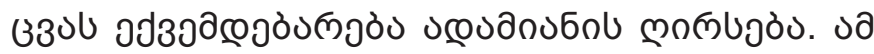

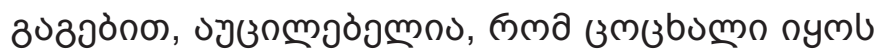

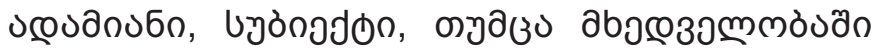

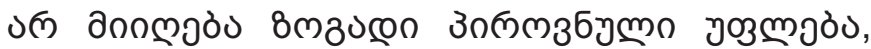

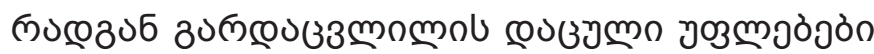

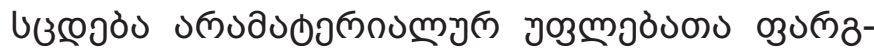

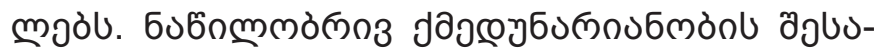

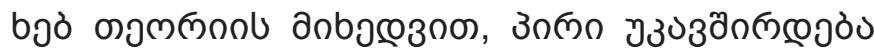

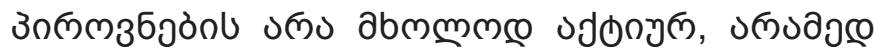

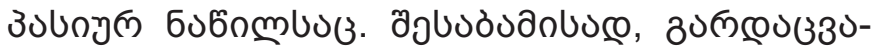

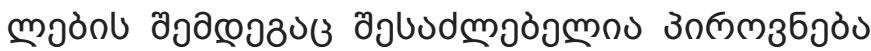

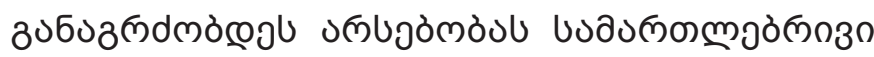

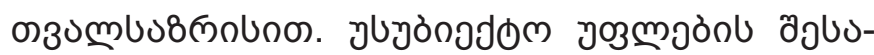

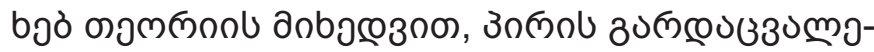

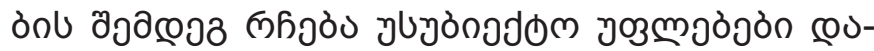

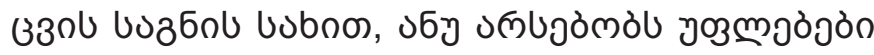

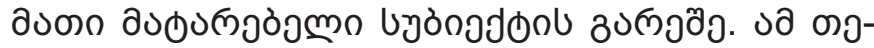

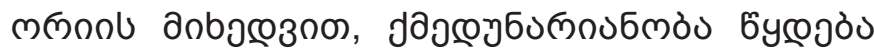

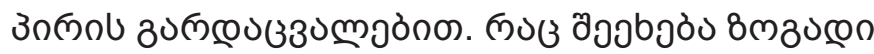

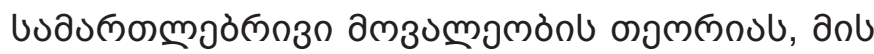

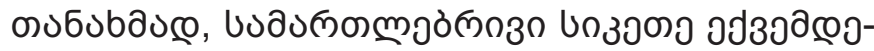

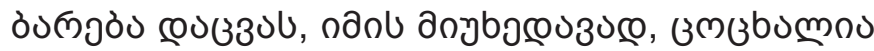

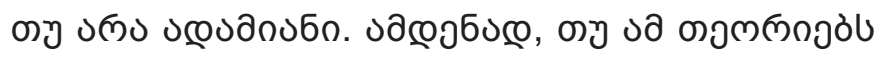

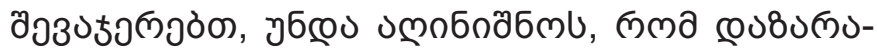

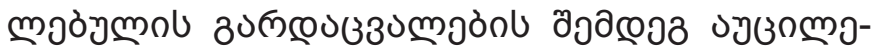

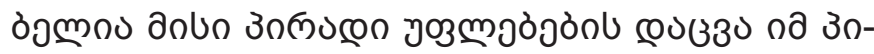

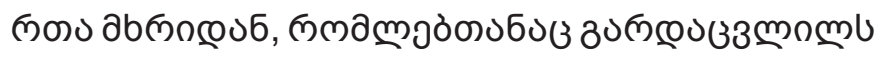

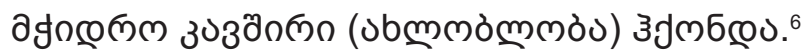

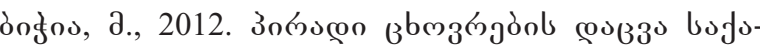

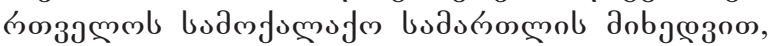
oònmolo, $33.247-249,259$.

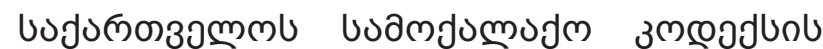

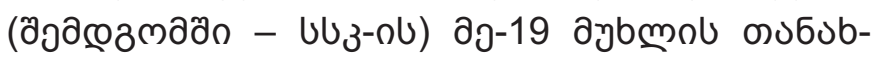

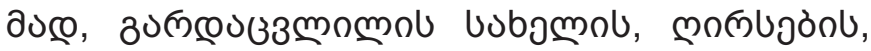

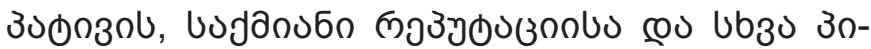

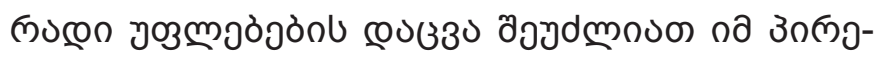

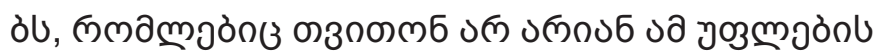

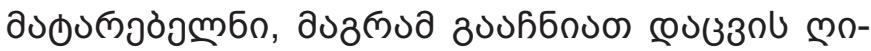

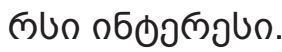

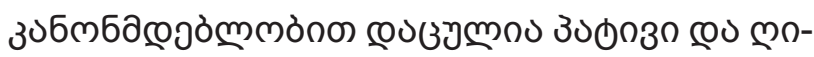

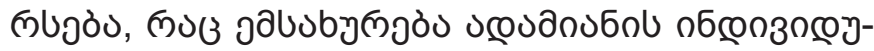

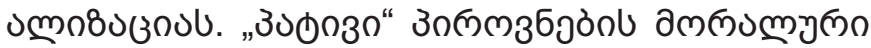

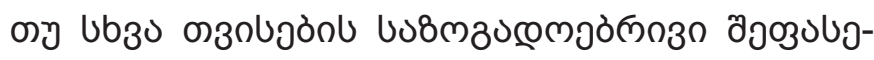

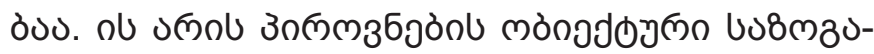

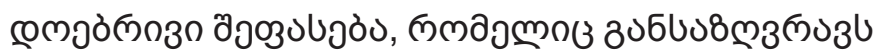

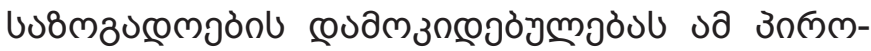

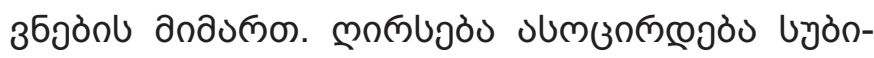

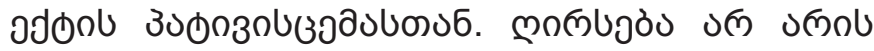

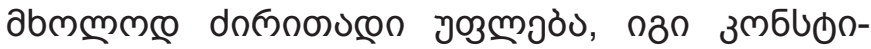

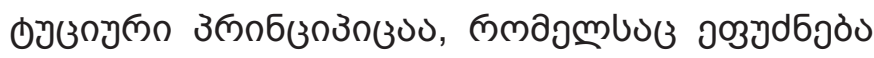

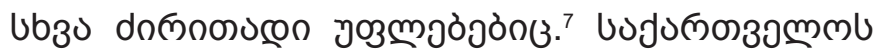

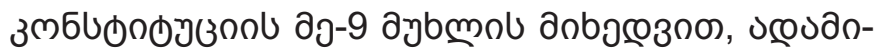

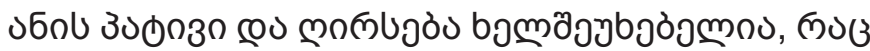

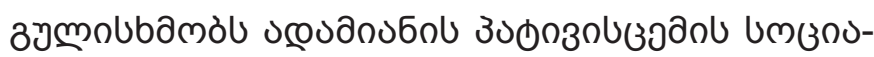

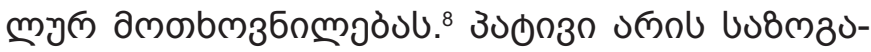

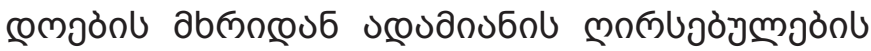

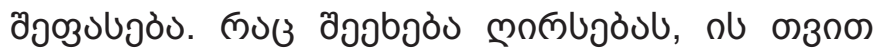

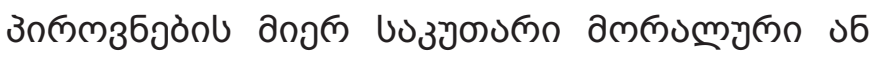

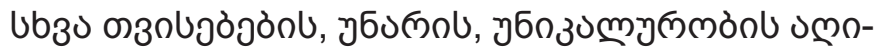

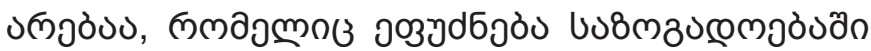

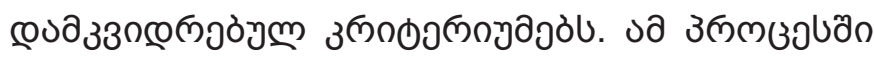

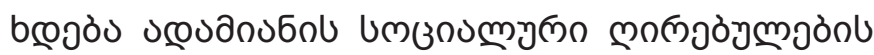

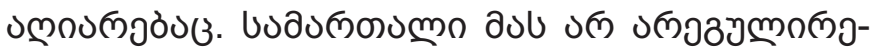

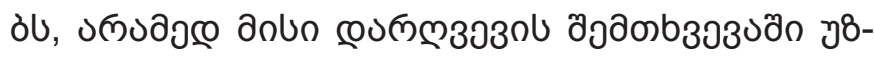

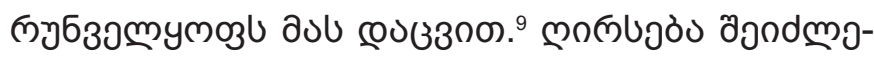

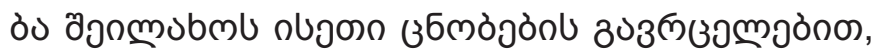

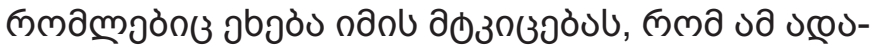

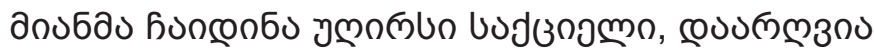

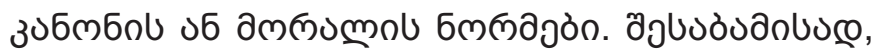

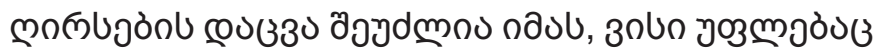

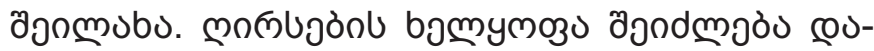

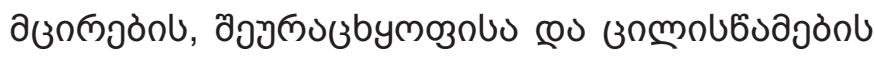

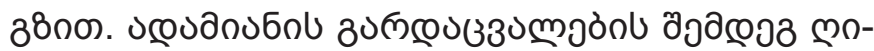

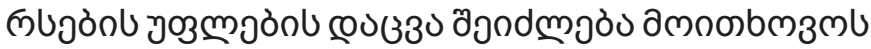

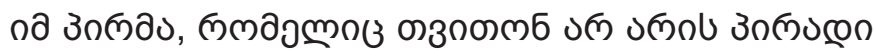

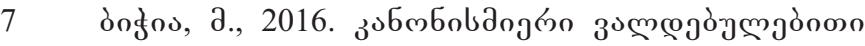

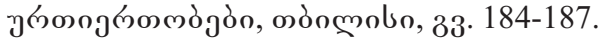

8 Ciorap v. Moldova, 19/07/2007, ECHR, App. No. 12066/02

9 Gäfgen v. Germany, 01/07/2010, ECHR, App. No 22978/05.
} 


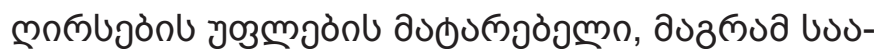

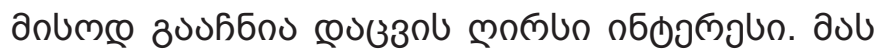

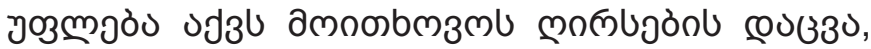

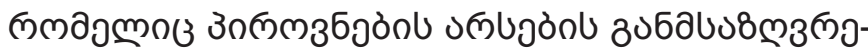

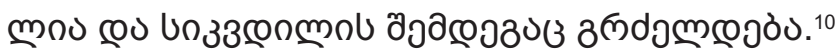

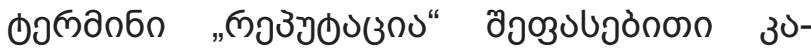

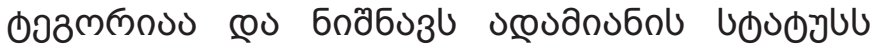

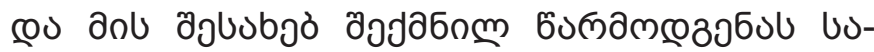

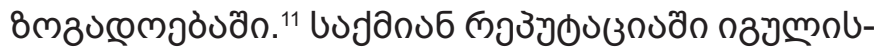

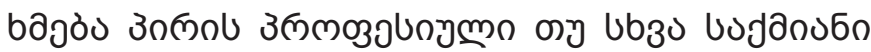

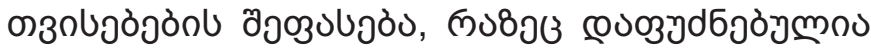

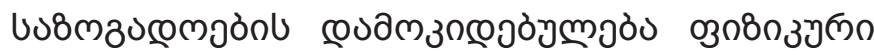

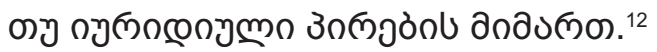

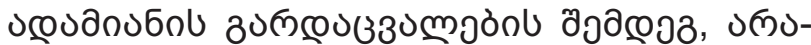

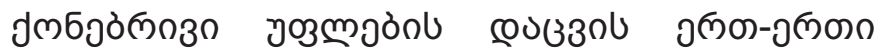

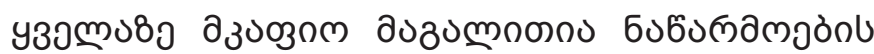

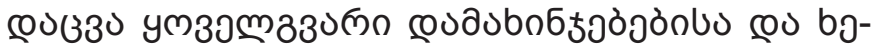

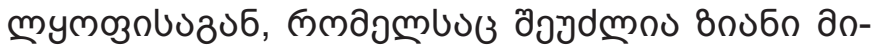

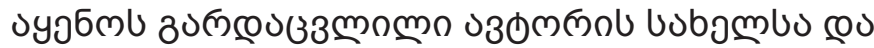

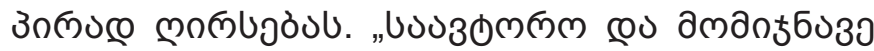

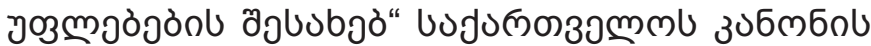

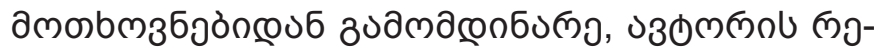

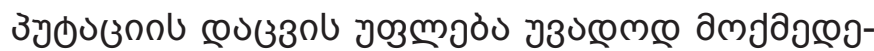

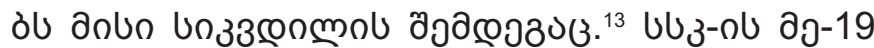

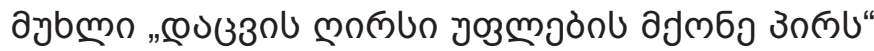

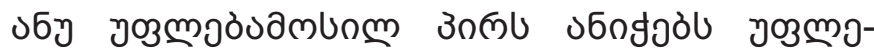

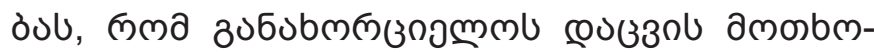

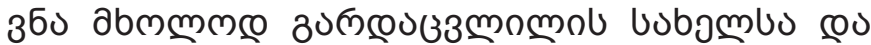

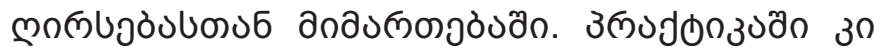

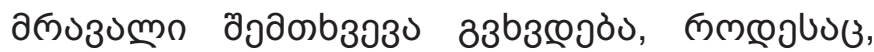

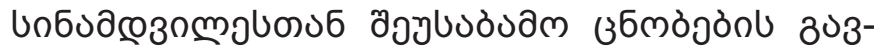

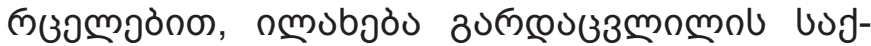

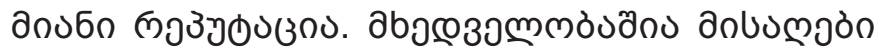

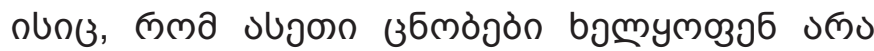

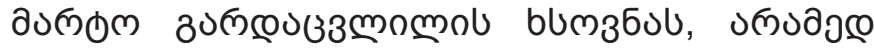

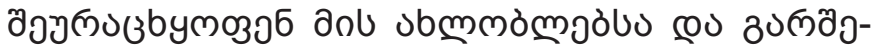

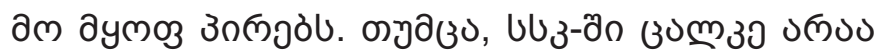

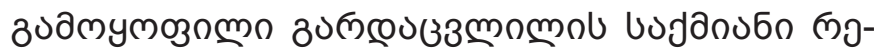

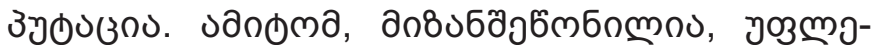

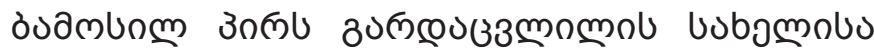

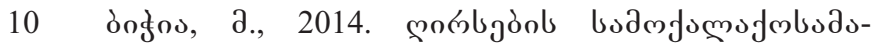

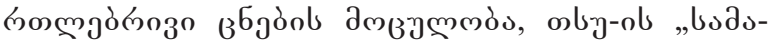

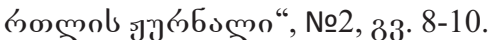

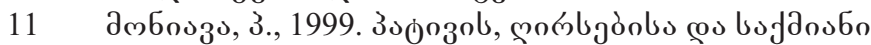

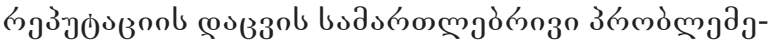

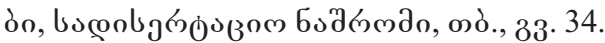

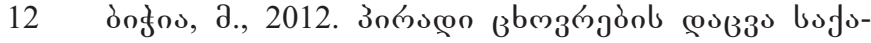

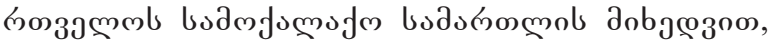
ò̀., 33. 159-162.

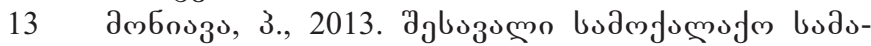

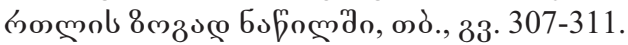

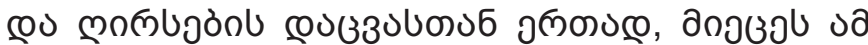

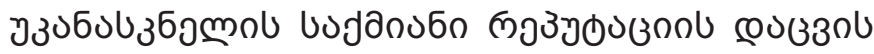

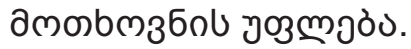

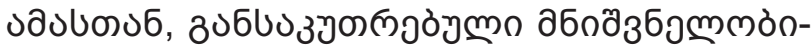

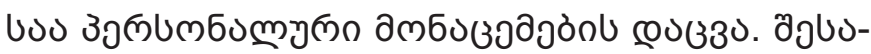

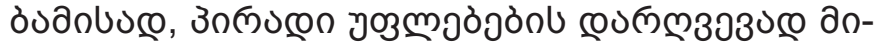

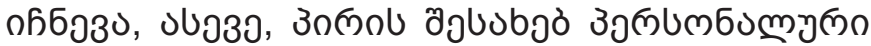

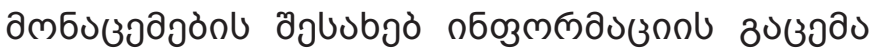

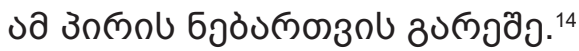

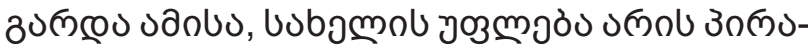

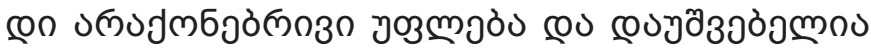

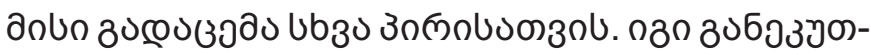

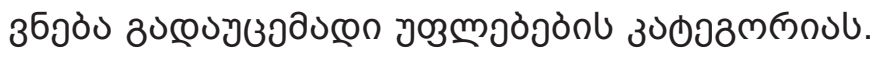

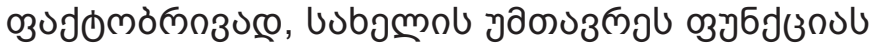

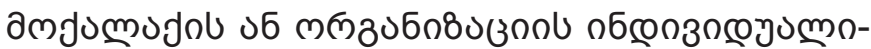

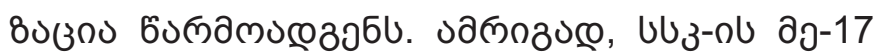

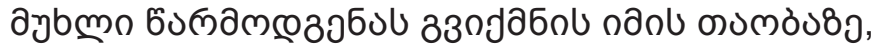

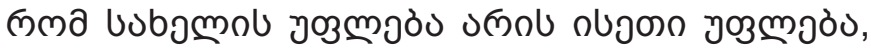

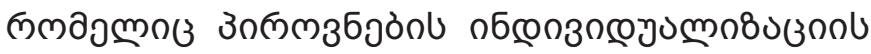

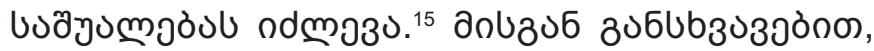

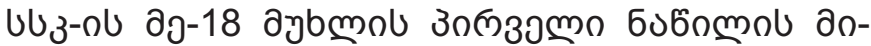

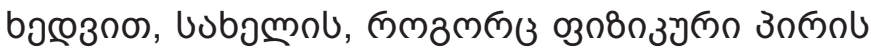

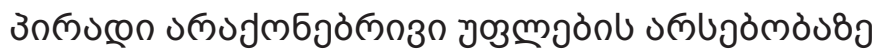

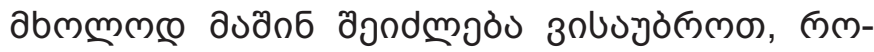

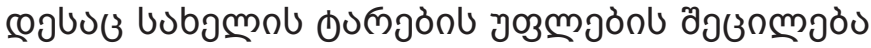

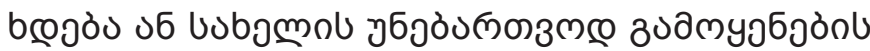

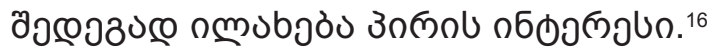

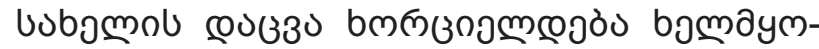

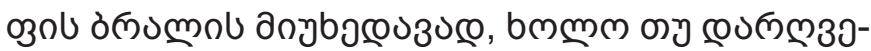

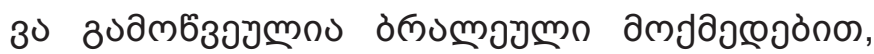

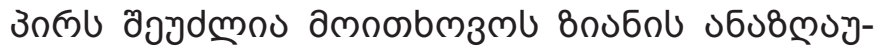
लоòos. ${ }^{17}$

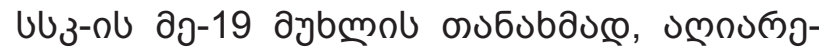

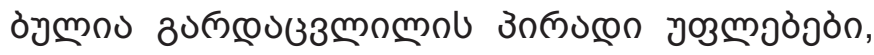

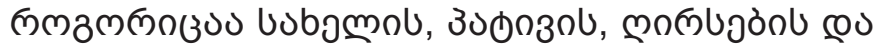

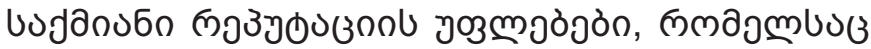

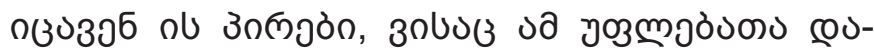

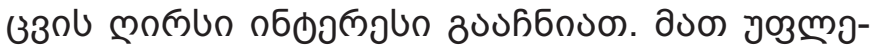

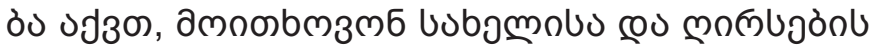

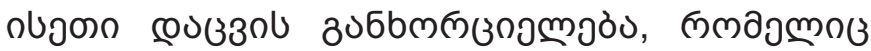

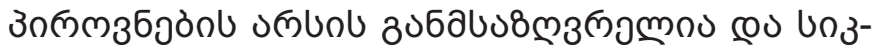

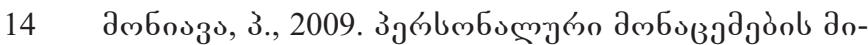

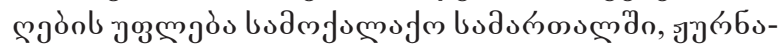

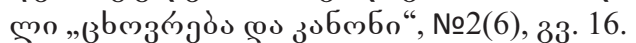

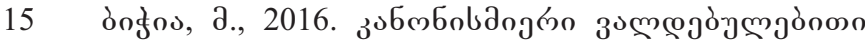

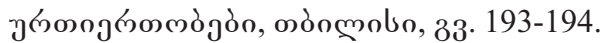

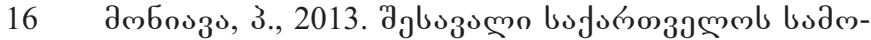

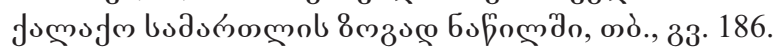

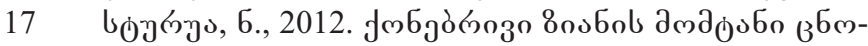

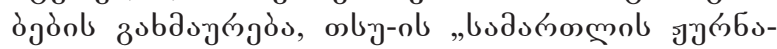
mo“", №1, 33. 152. 


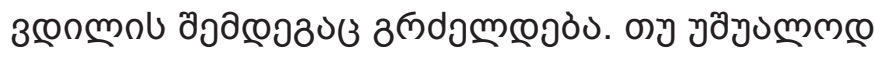

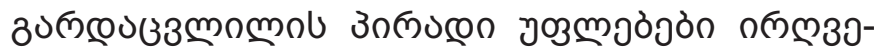

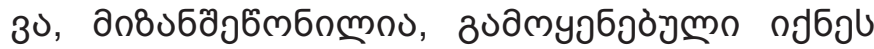

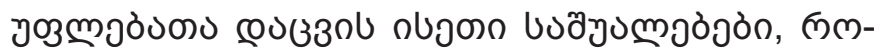

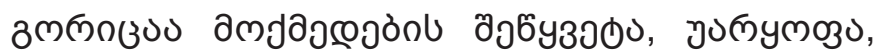

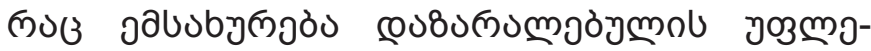

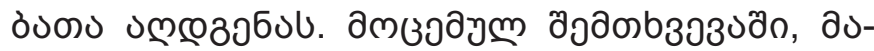

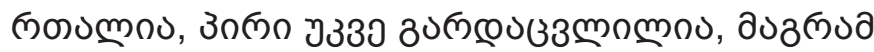

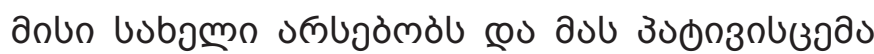

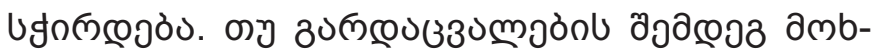

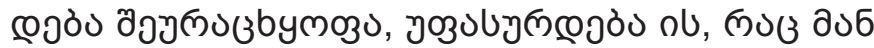

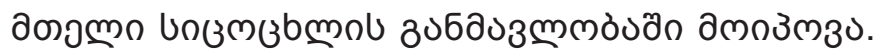

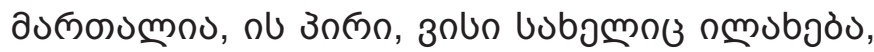

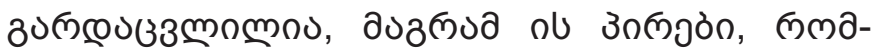

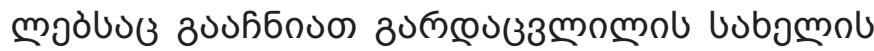

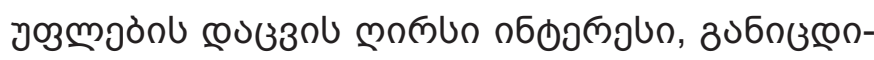

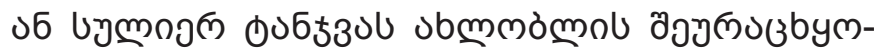

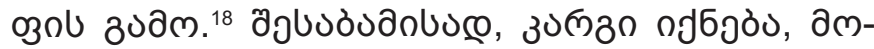

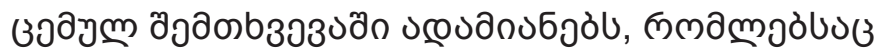

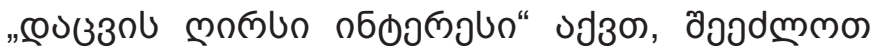

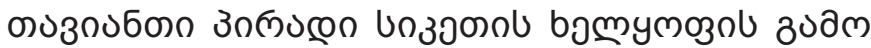

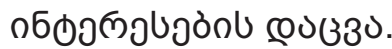

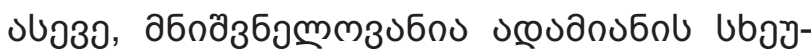

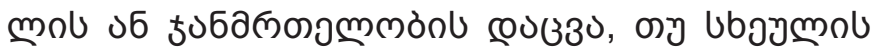

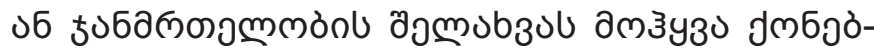

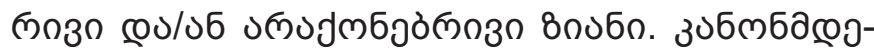

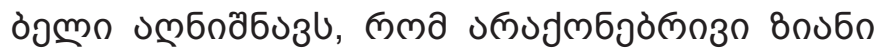

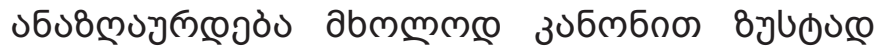

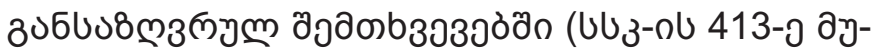

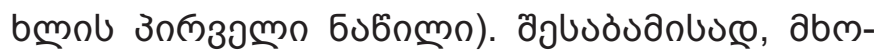

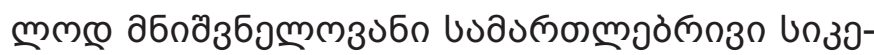

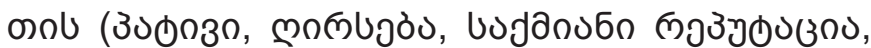

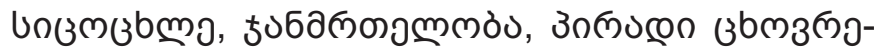

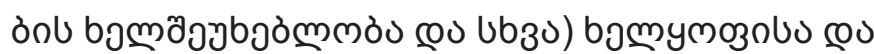

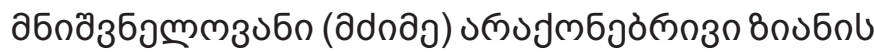

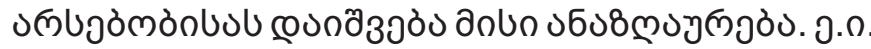

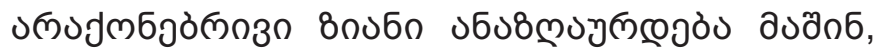

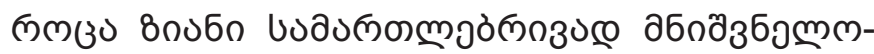

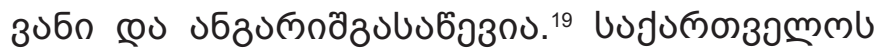

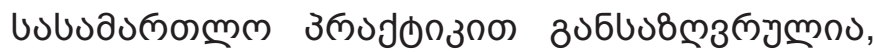

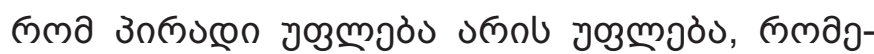

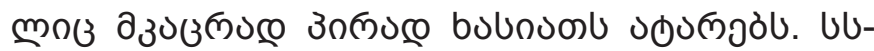

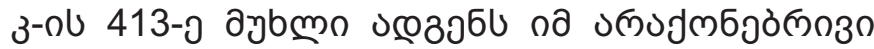

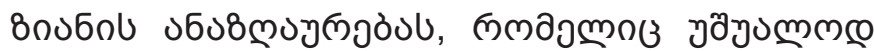

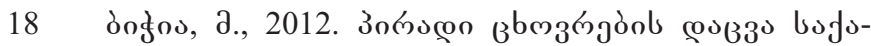

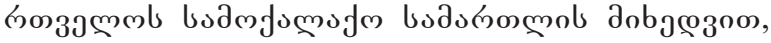
oòngmolo, 33. 254-258.

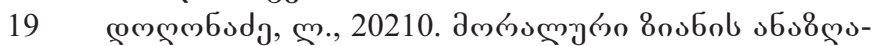

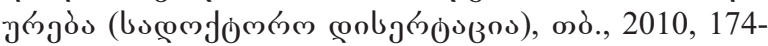
175,181

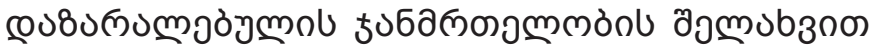

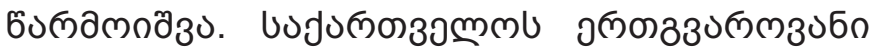

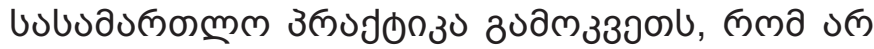

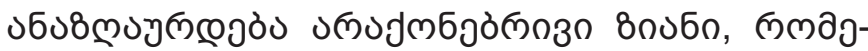

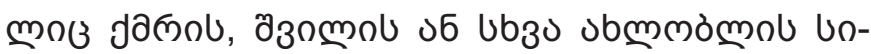

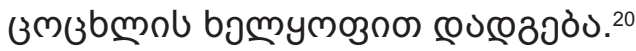

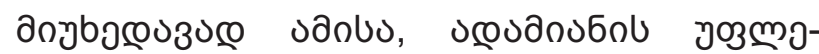

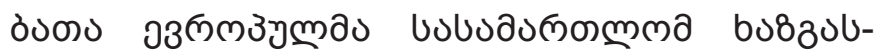

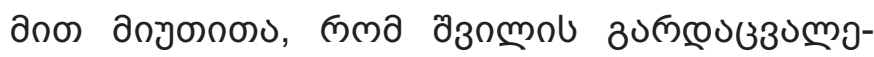

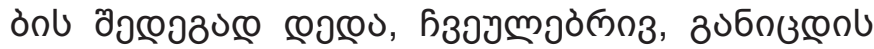

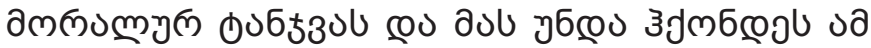

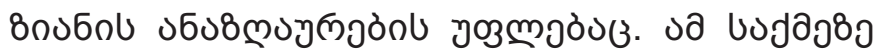

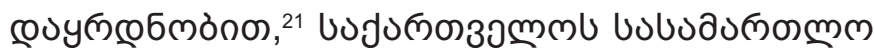

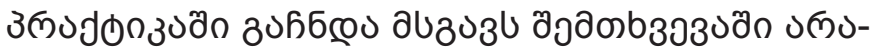

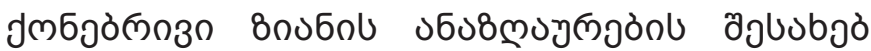
аง

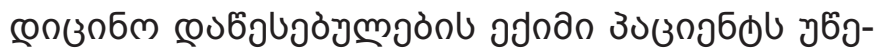

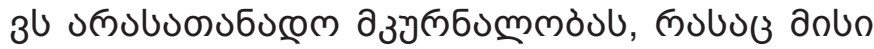

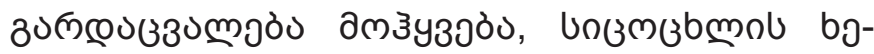

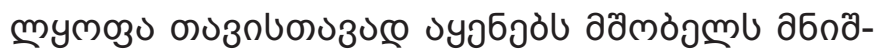

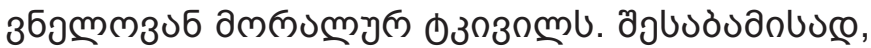

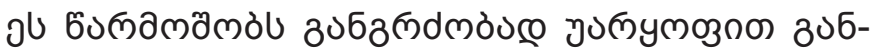
з

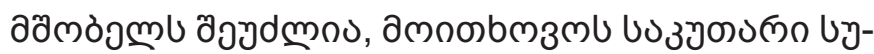

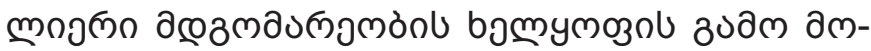

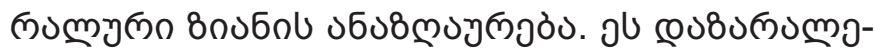

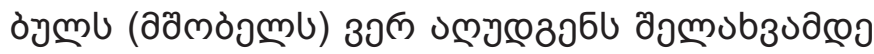

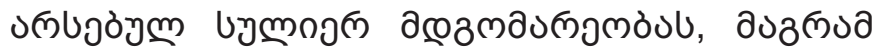

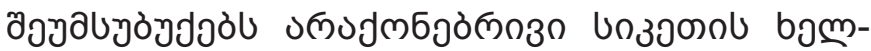

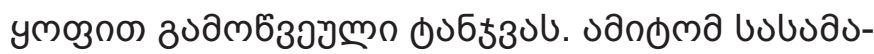

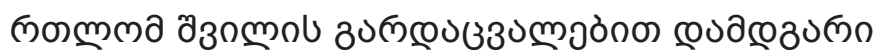

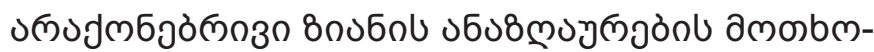
350 ㅇos za y y

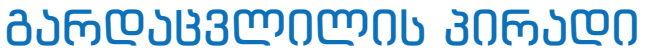

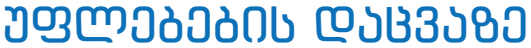

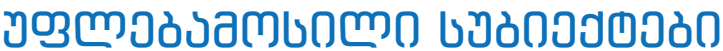

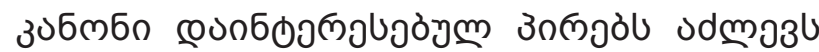

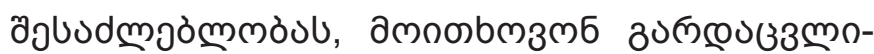

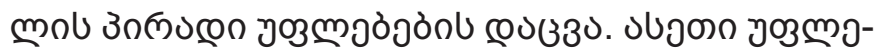

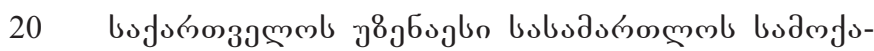
mofm bofagos 3 a mojoll 2017 fmols 14 ozmobnls

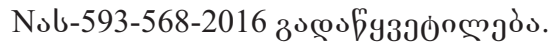

21 Case of Sarishvili-Bolkvadze v. Georgia, [19.07.2018], ECHR, App. №58240/08.

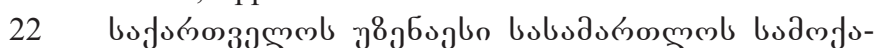

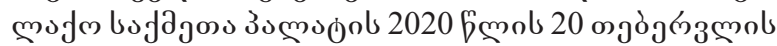

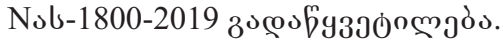




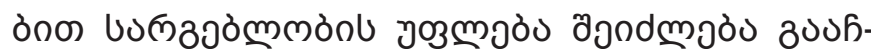

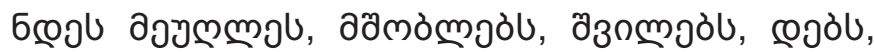

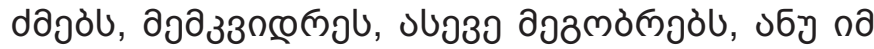

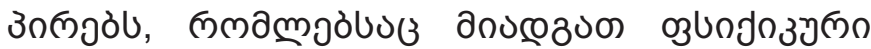

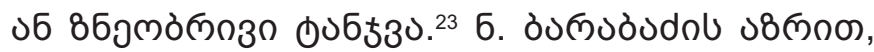

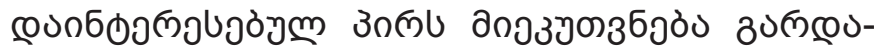

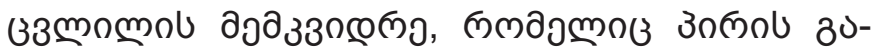

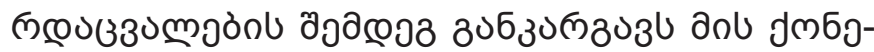

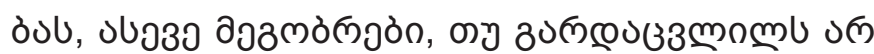

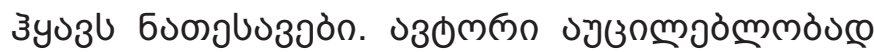

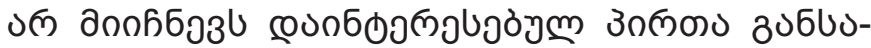

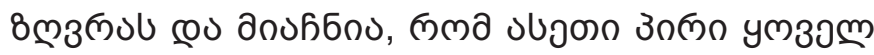

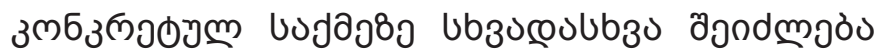
oymb. ${ }^{24}$

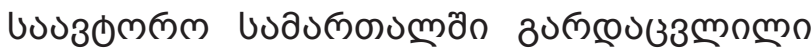

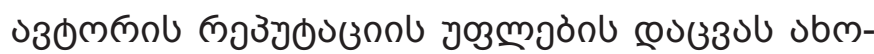

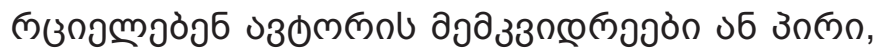

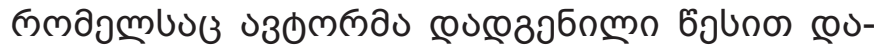

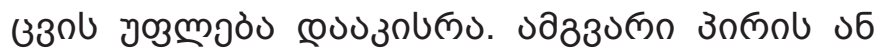

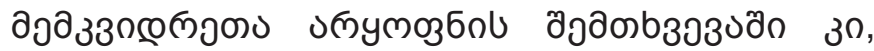

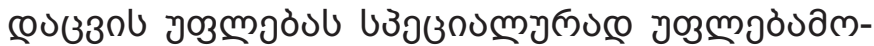

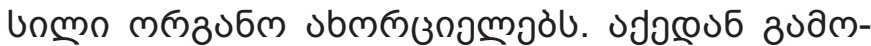

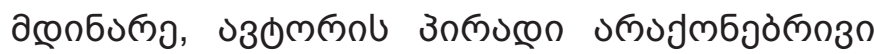

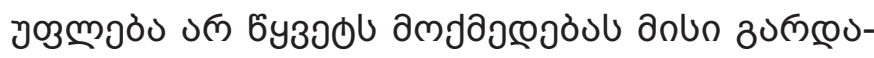

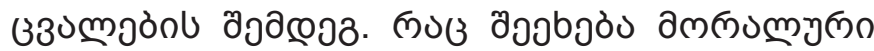

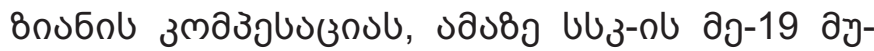

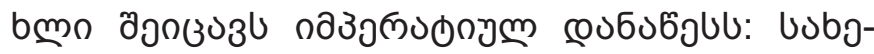

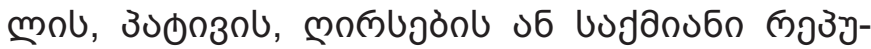

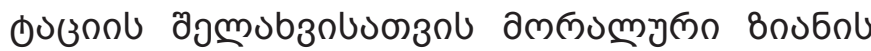

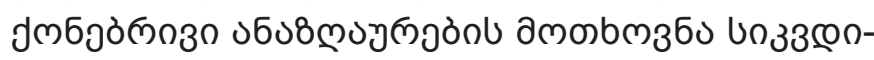

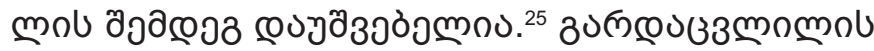

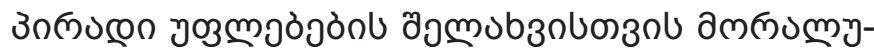

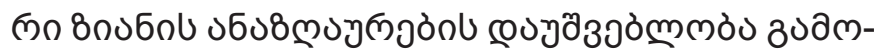

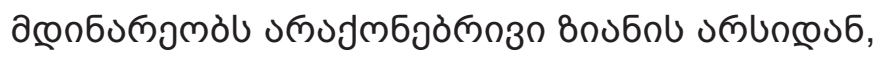

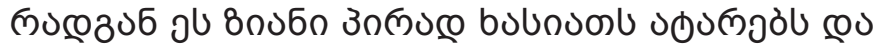

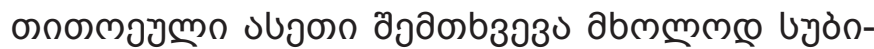

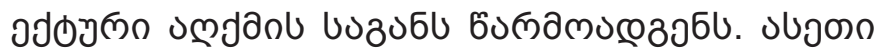

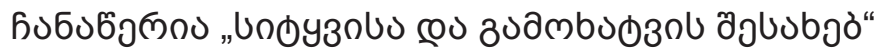

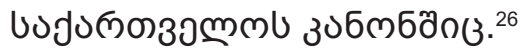

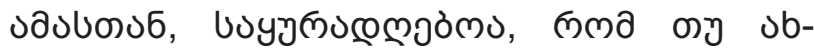

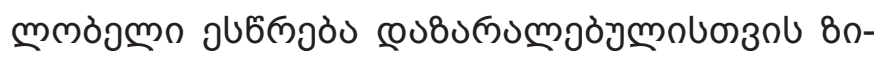

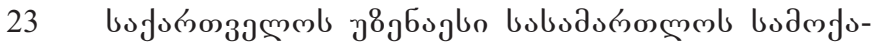

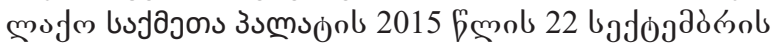

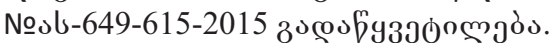

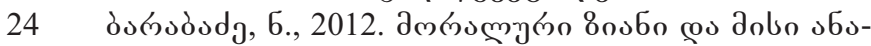

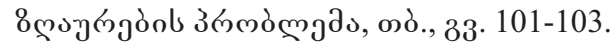

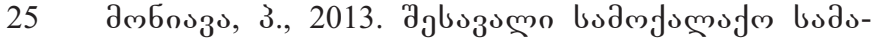

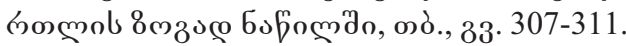

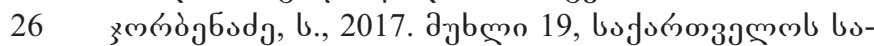

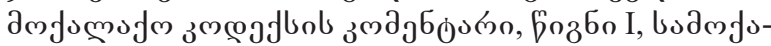

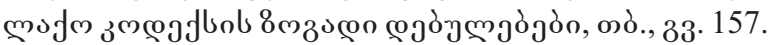

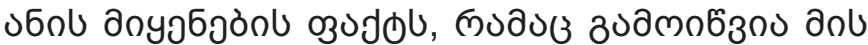

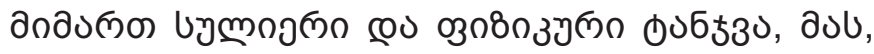

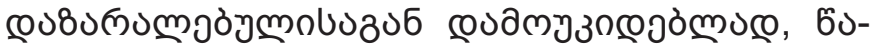

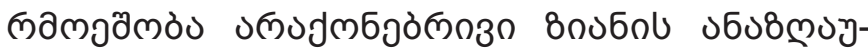

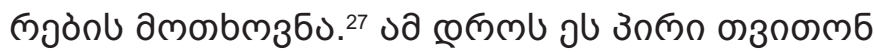

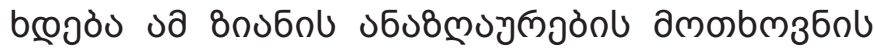

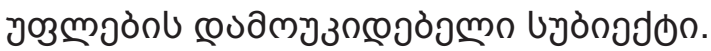

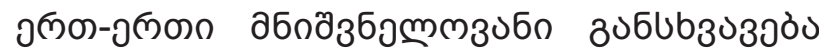

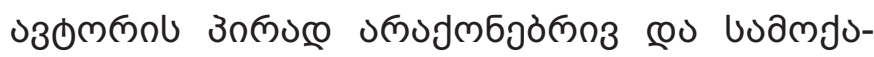

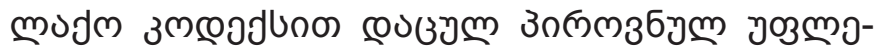

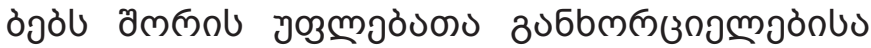

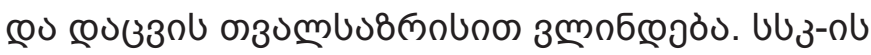

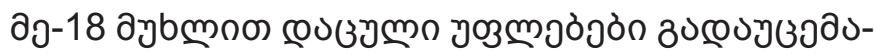

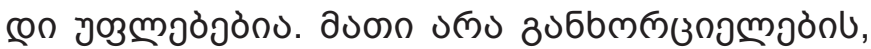

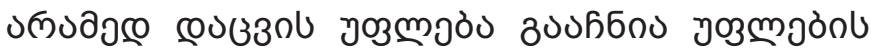

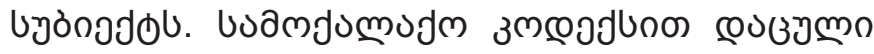

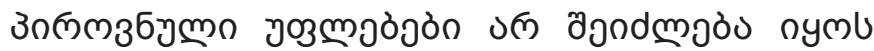

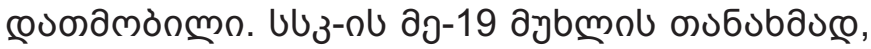

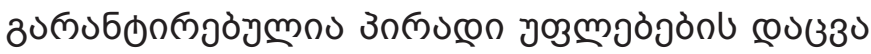

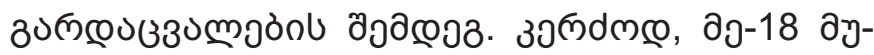

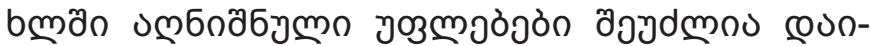

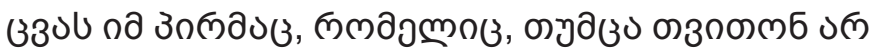

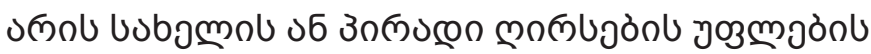

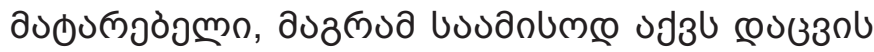

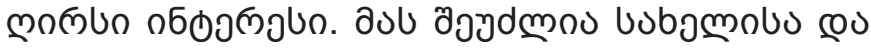
monujòn o

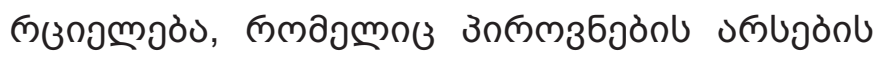

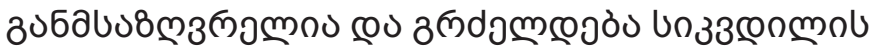

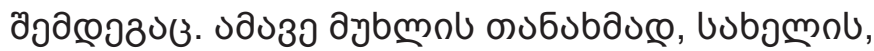

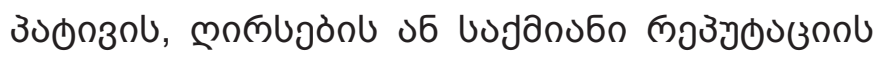

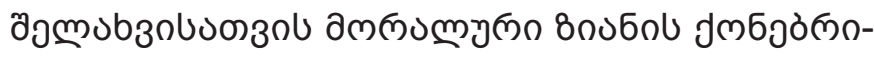

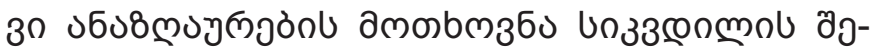

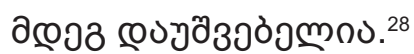

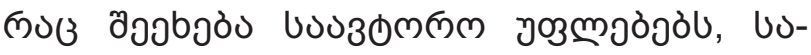

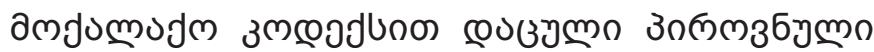

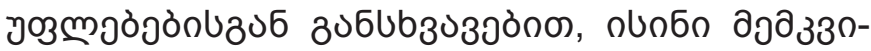

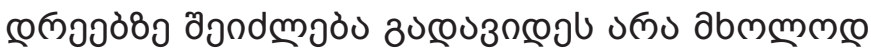

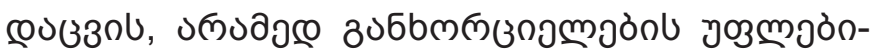

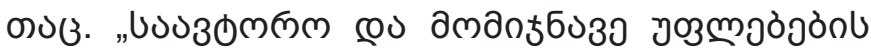

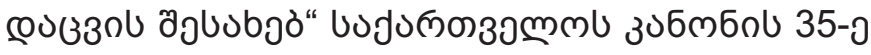

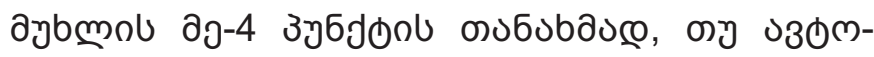

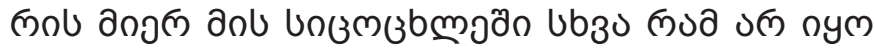

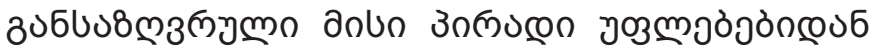

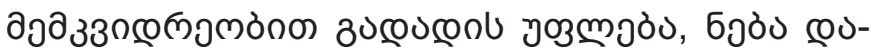

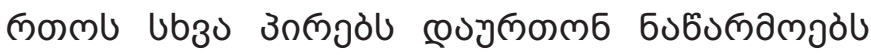

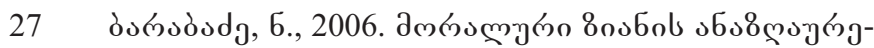

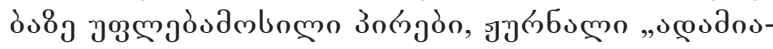

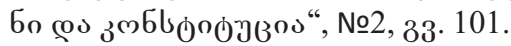

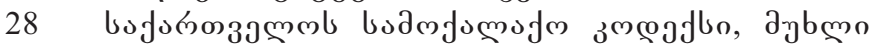
19. 


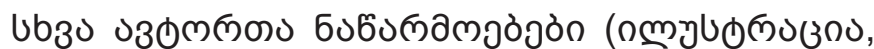

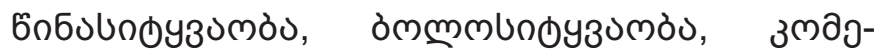

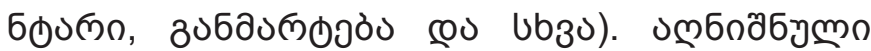

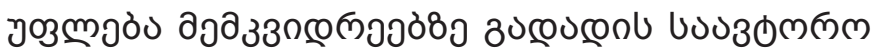

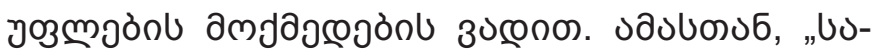

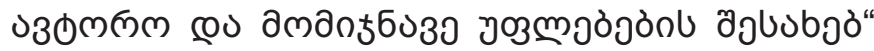

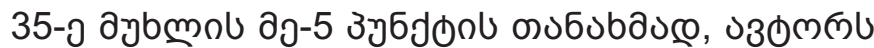

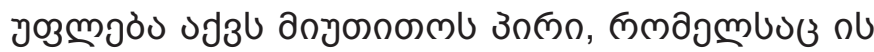

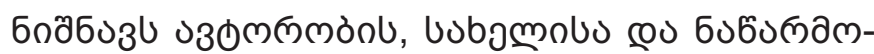

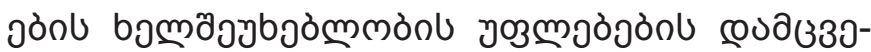

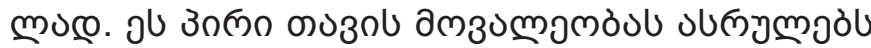

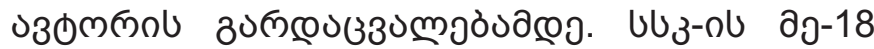

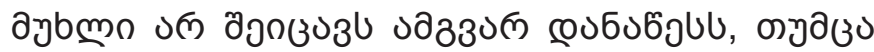

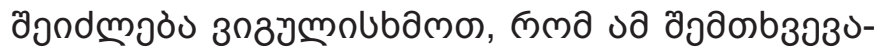

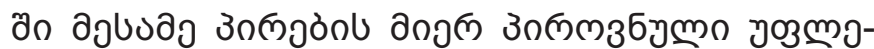

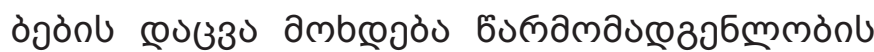

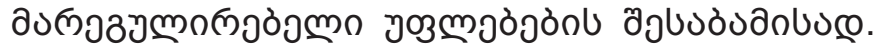

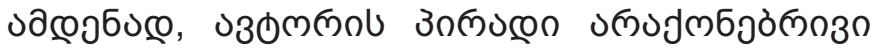

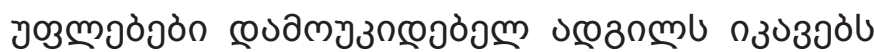

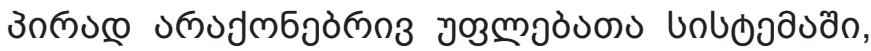

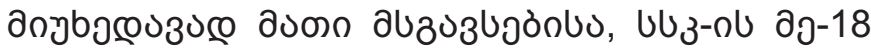

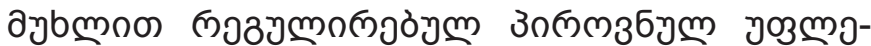

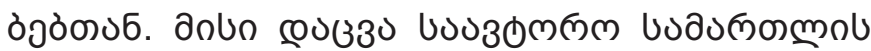

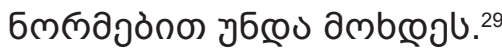

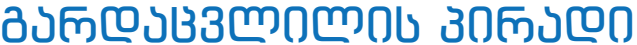

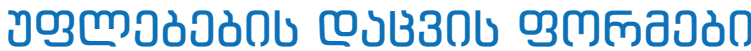

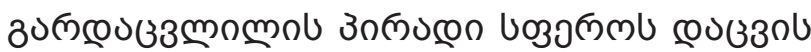

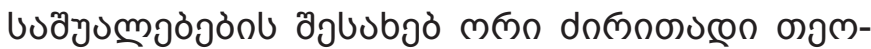

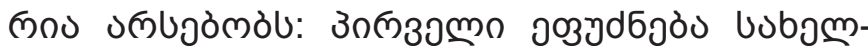

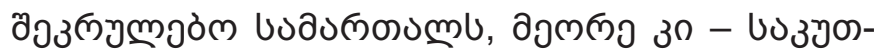

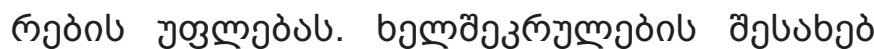

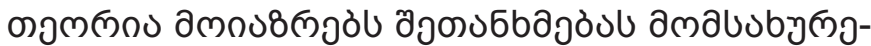

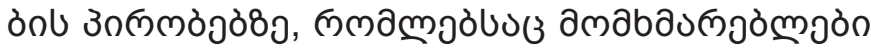

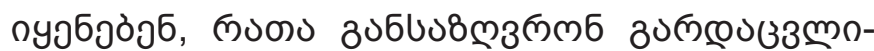

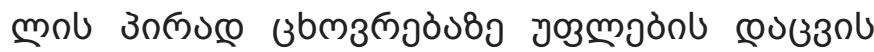

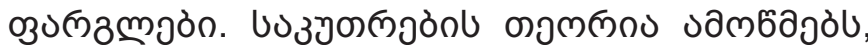

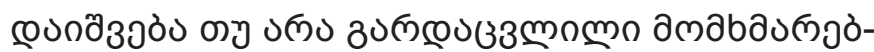

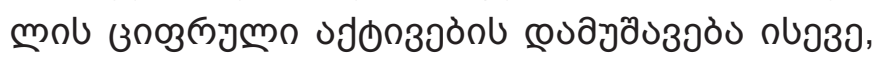

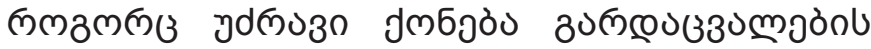

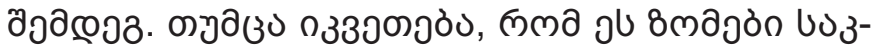

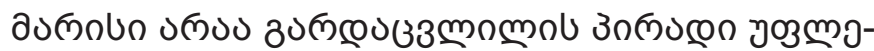

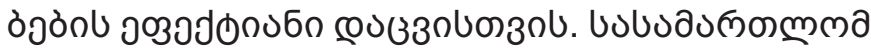

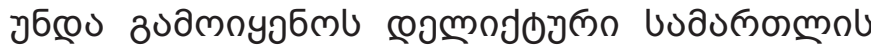

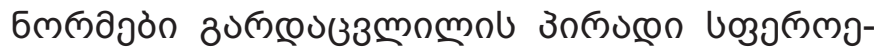

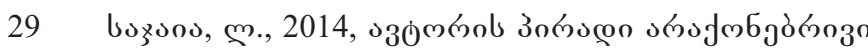

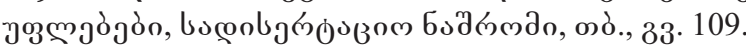

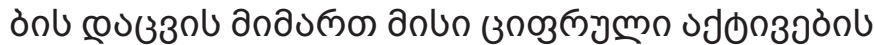

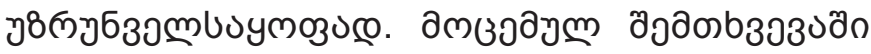

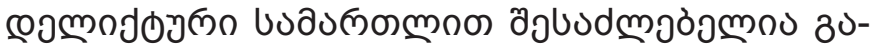

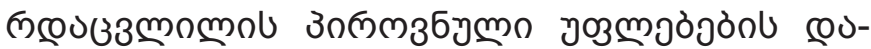

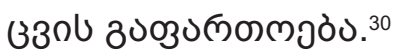

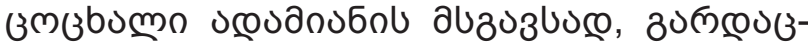

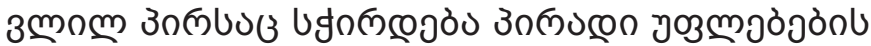
cou330. couso

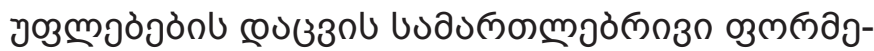

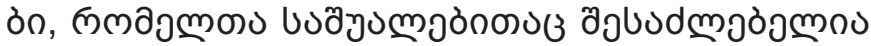

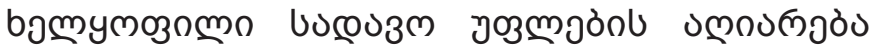

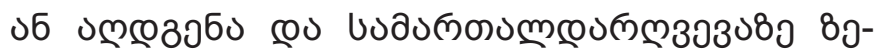

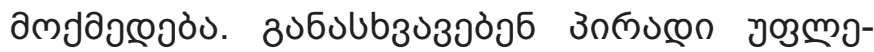

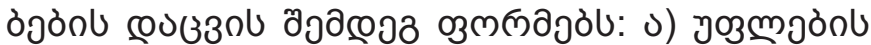

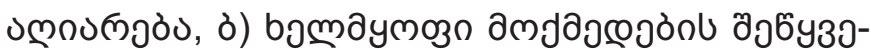

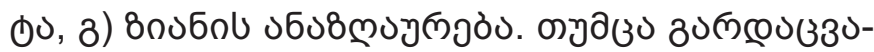

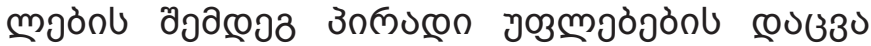

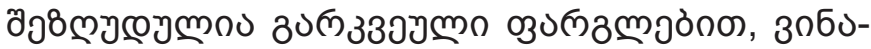

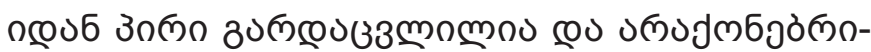

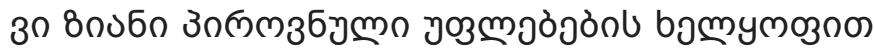

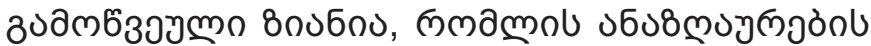

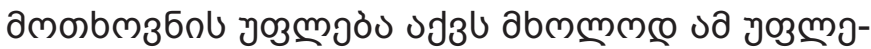

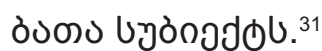

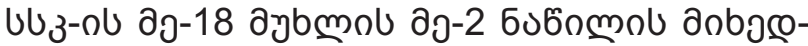

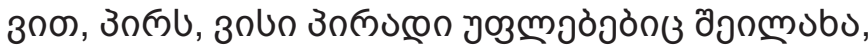

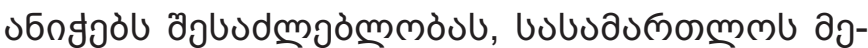

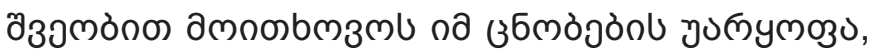

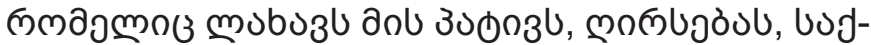

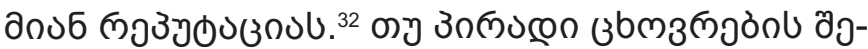

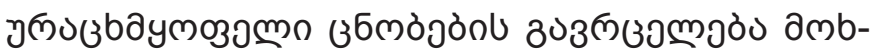

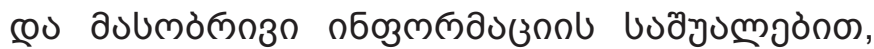

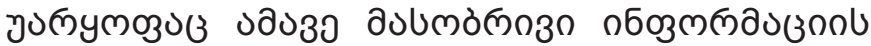

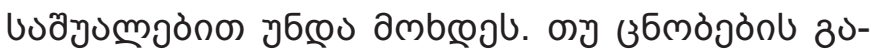

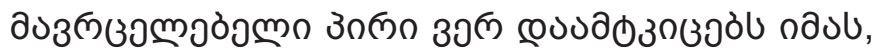

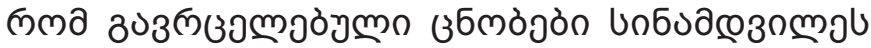

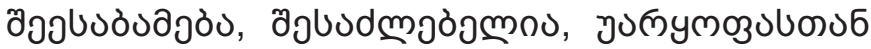

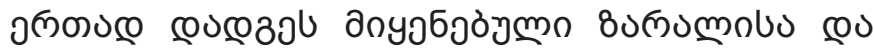

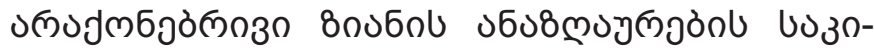

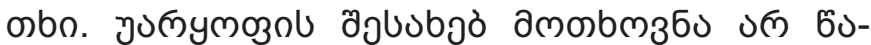

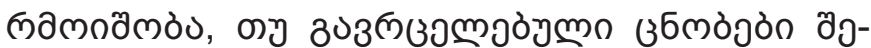

30 Chu, N., 2015. Protecting Privacy after Death, 13 Northwestern Journal of Technology and intellectual property,Vol.13, Iss.2, p. 255.

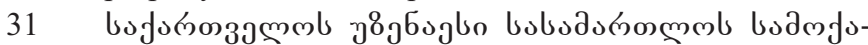

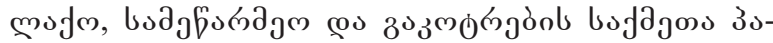

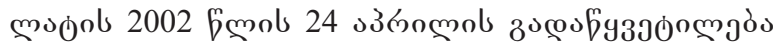
(№3 3-1218-01).

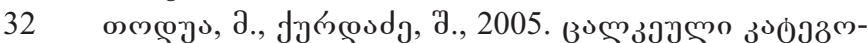

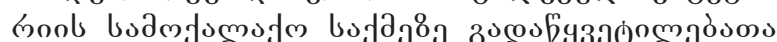

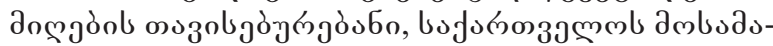

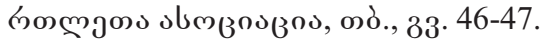




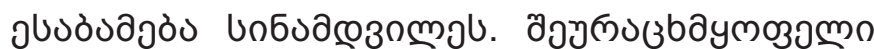

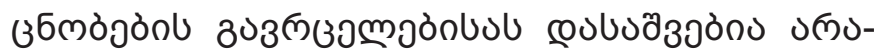

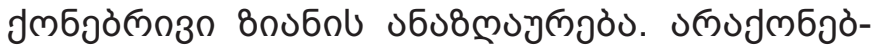

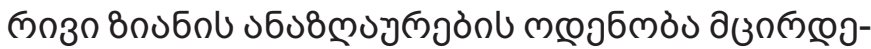

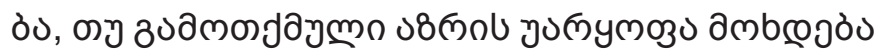

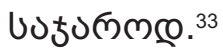

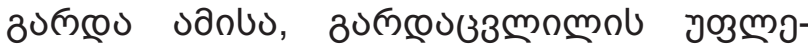

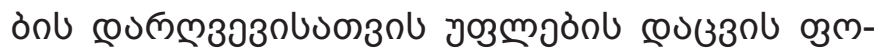

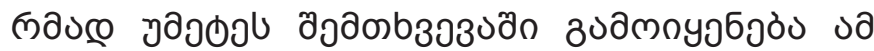

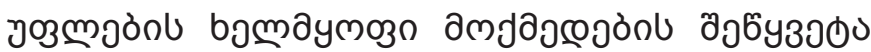

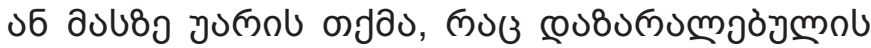

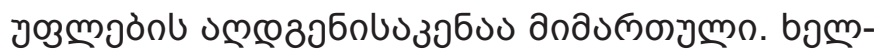

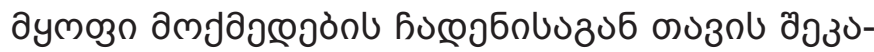

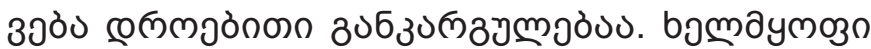

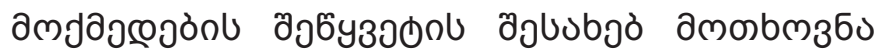

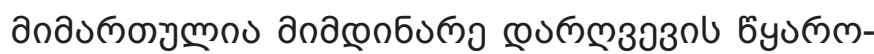

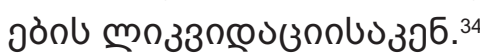

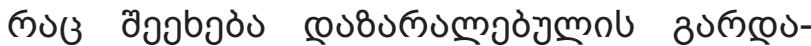

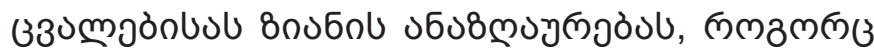

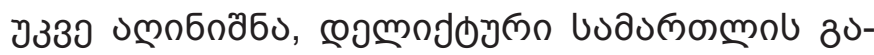

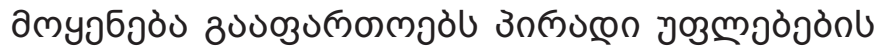

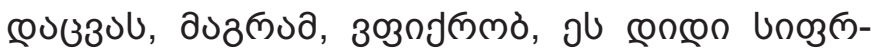

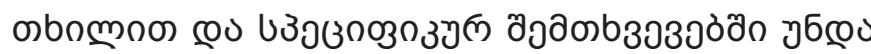

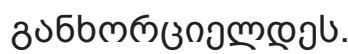

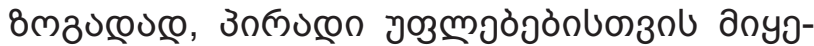

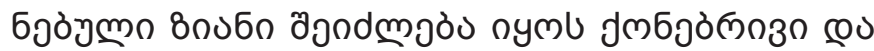

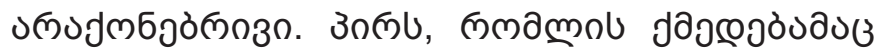

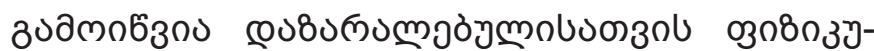

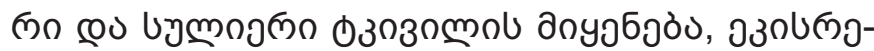

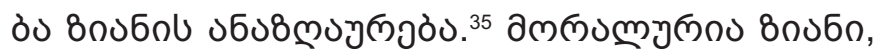

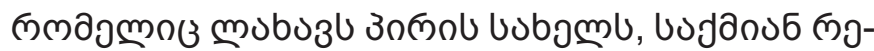

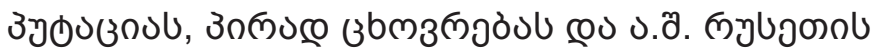

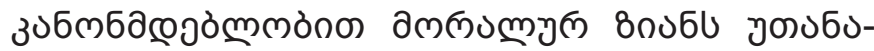

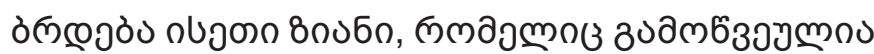

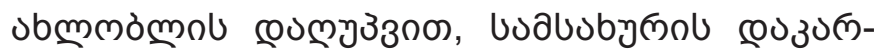

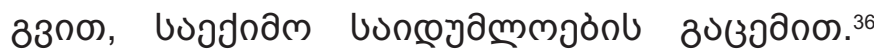

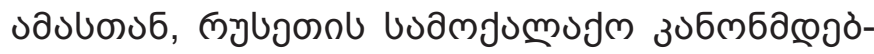

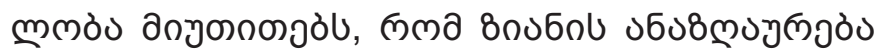

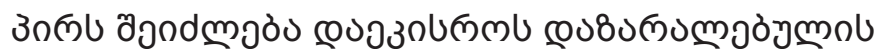

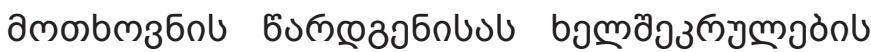

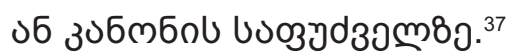

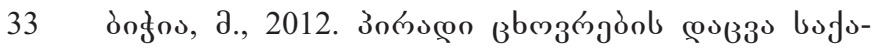

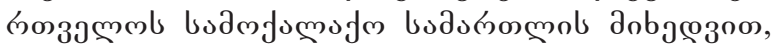
оò., 33. 230-233.

34 oł39, 33. 197-199, 227-229.

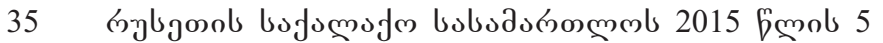

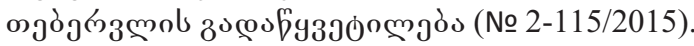

36 Кулешов, Г.В., 2003 г., Возмещение вреда, причиненного жизни и здоровью военнослужащего, Волгоград, стр. 124-129.

37

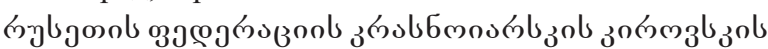

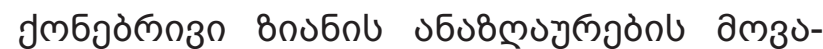

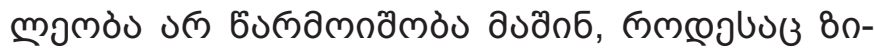

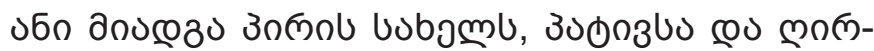

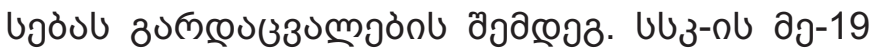

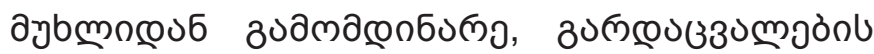

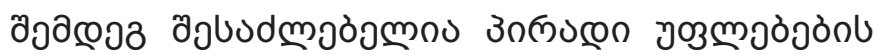

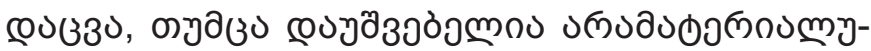

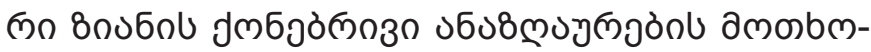

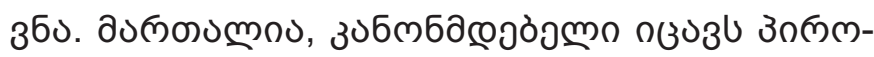

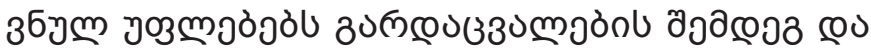

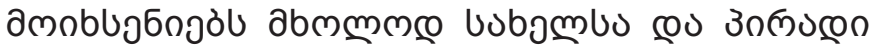

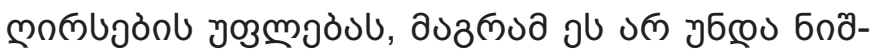

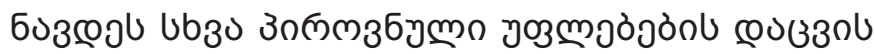

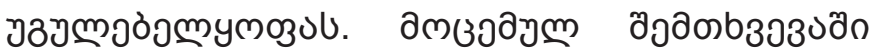

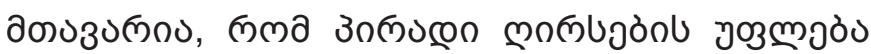

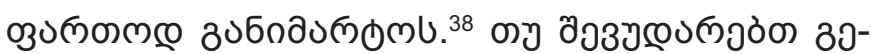

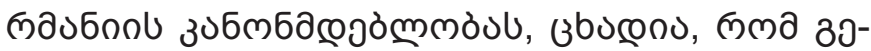

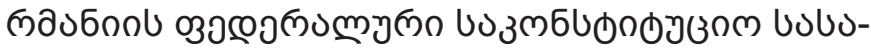

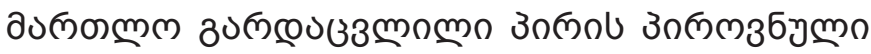

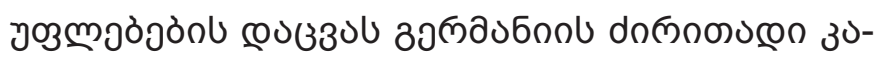

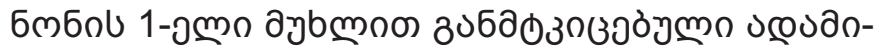

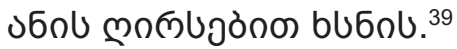

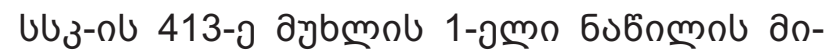

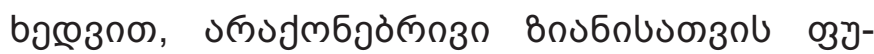

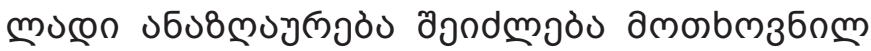

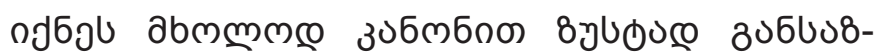

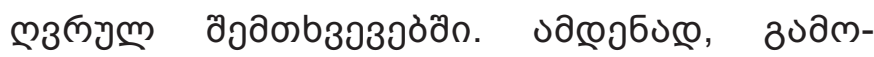

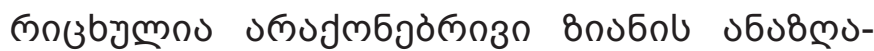

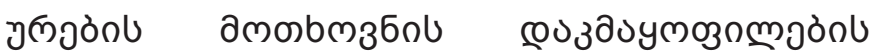

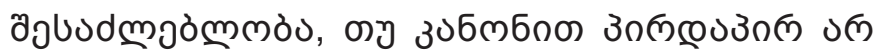

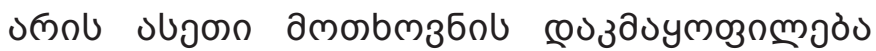

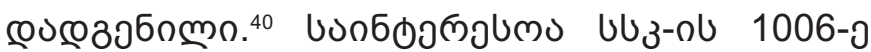

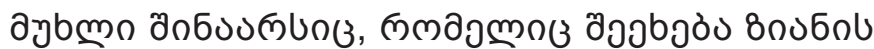

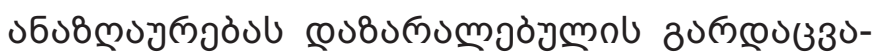

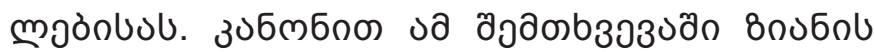

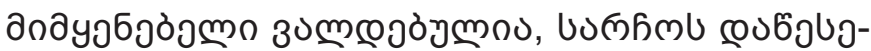

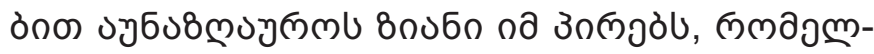

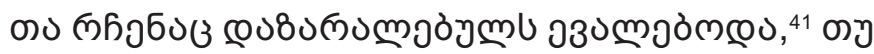

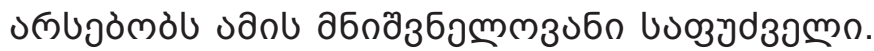

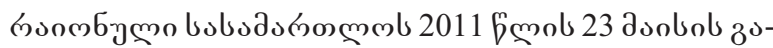

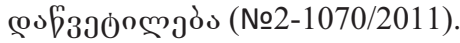

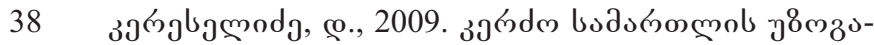

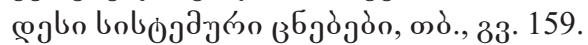

39 BVerfG, NJW, 1971,S.1645-1647.

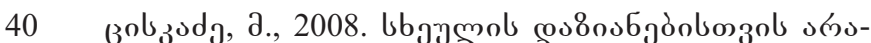

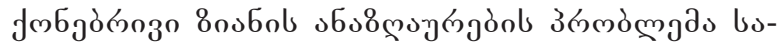

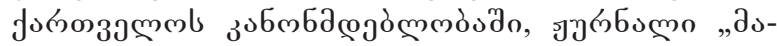

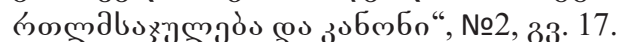

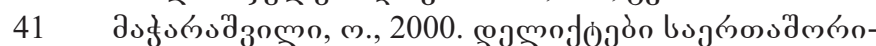

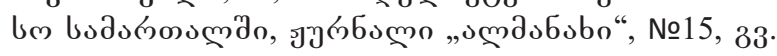
20-22. 


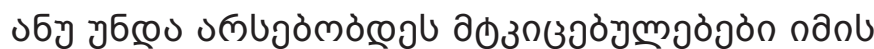

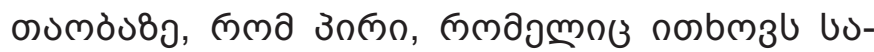

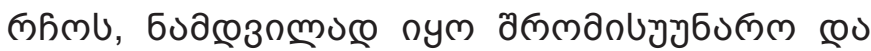

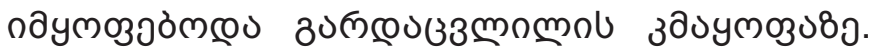

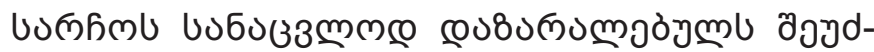

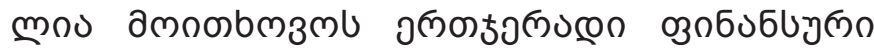

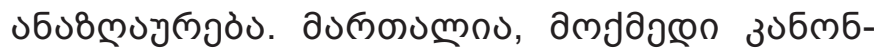

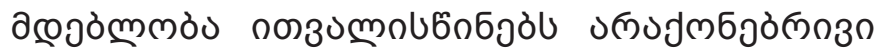

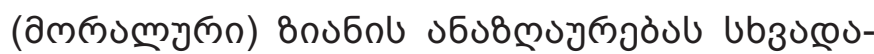

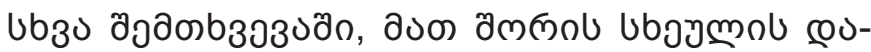

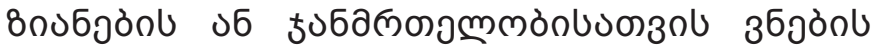

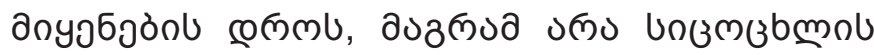

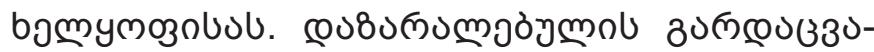

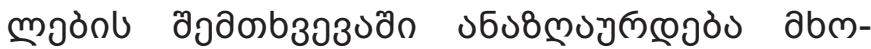

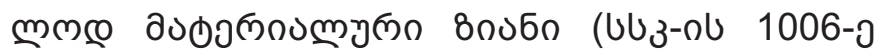

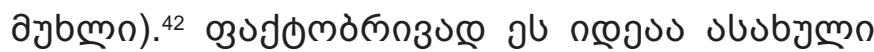

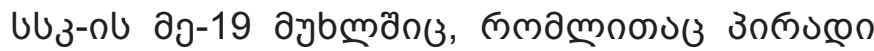

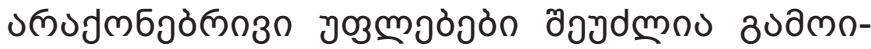

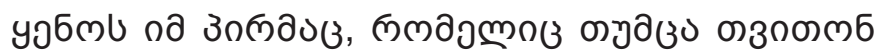

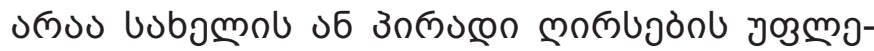

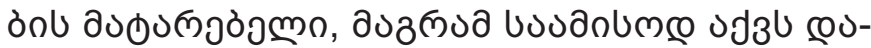

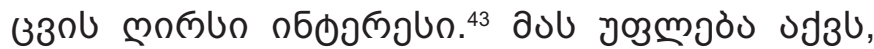

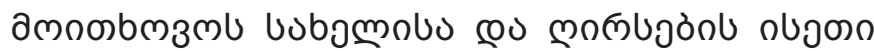

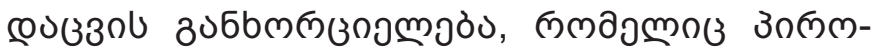

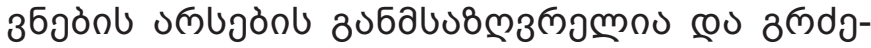

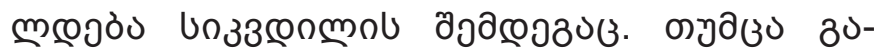

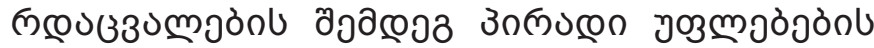

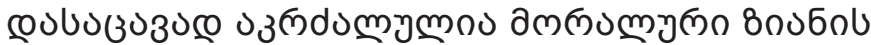

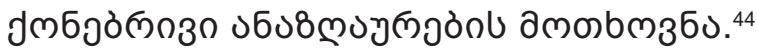

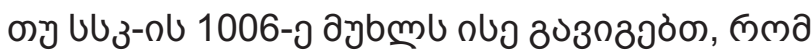

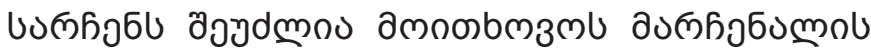

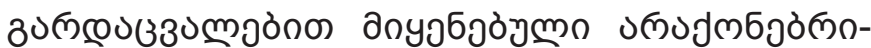

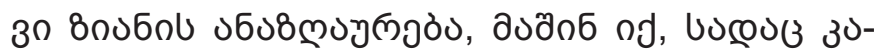

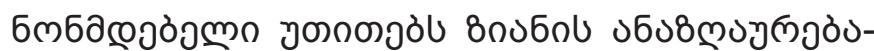

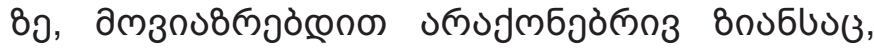

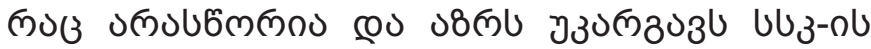

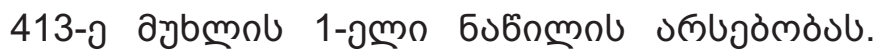

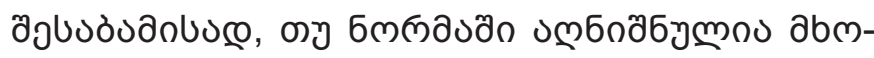

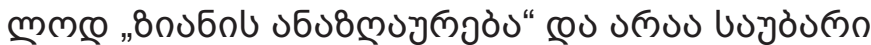

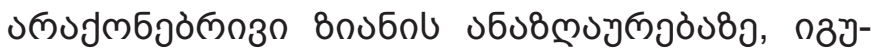

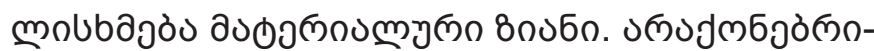

42 Бичия, М., 2016. Основания и объем возмещения вреда понесенного в случае смерти кормильца (Обзор судебной практики Грузии)., «Южнокавказский Юридический Журнал»,N7, стр. 130.

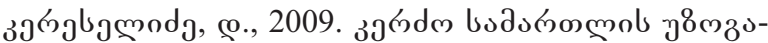

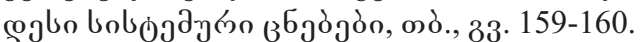

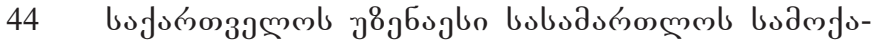

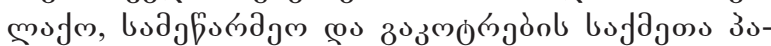

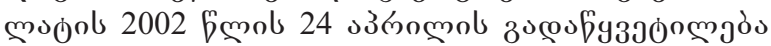
(№3 3 -1218-01).

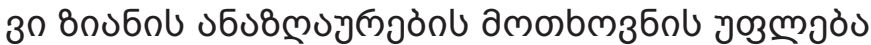

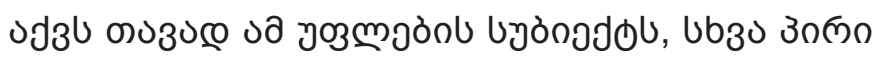

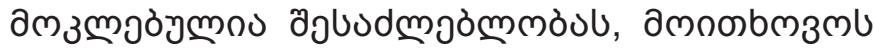

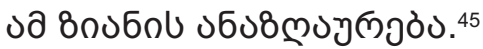

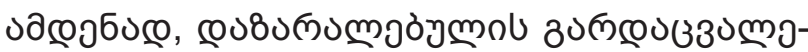

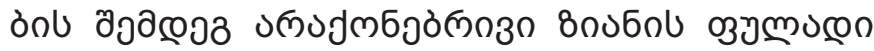

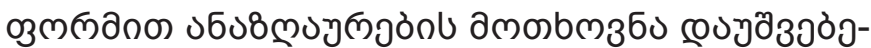

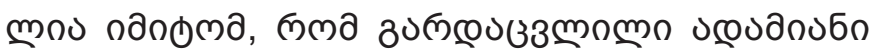

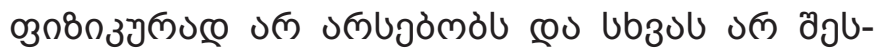

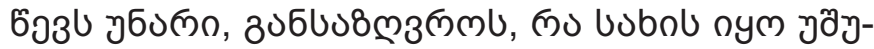

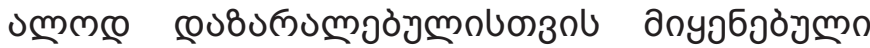

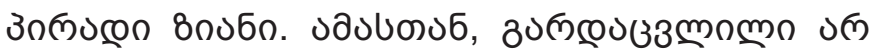

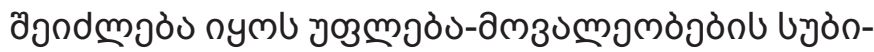

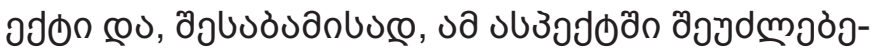

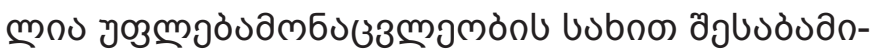

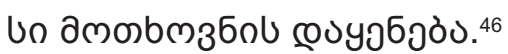

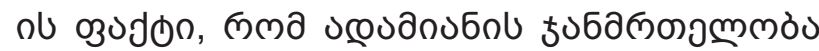

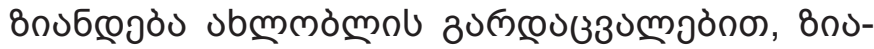

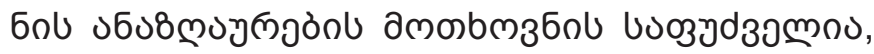

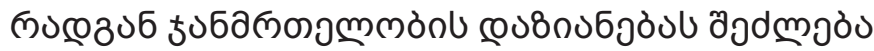

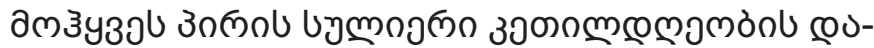

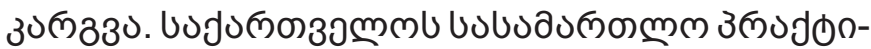

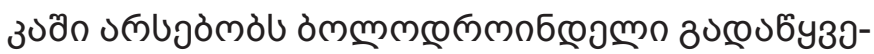

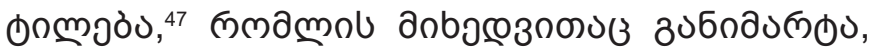

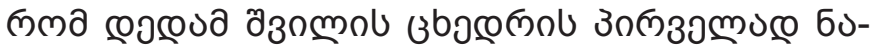

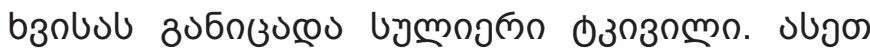

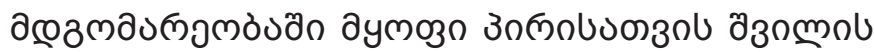

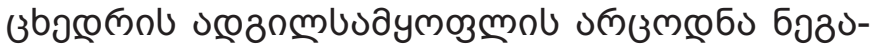

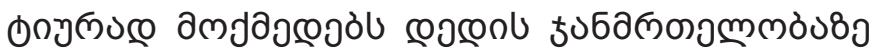

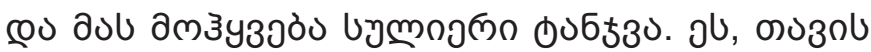

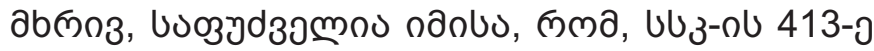

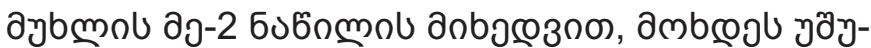

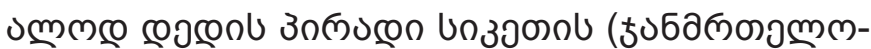

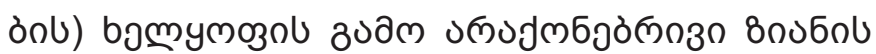

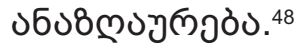

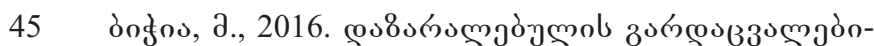

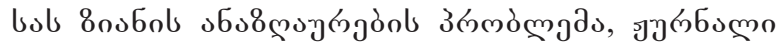

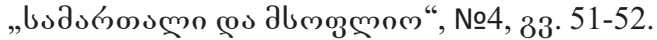

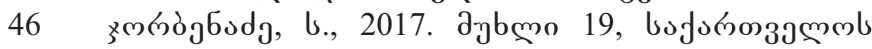

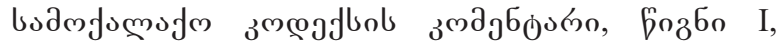

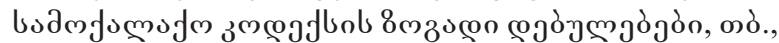
33.158 .

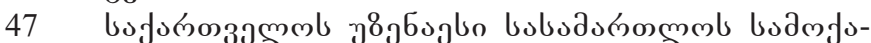

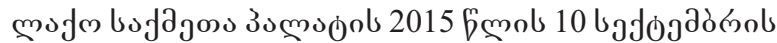

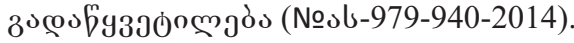

48 Bichia, M., 2016. Analysis of Georgian Judicial Practice on the Grounds and Scope of Compensation of Damages Incurred by the Death of a Breadwinner,South Caucasus Law Journal, N7, 283-284. 


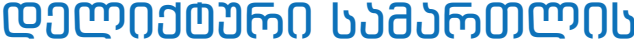

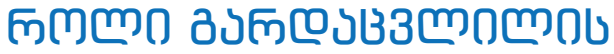

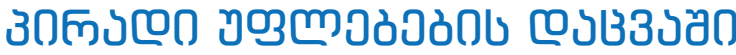

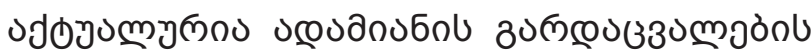

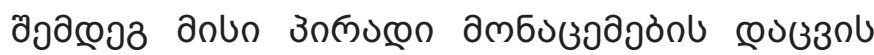

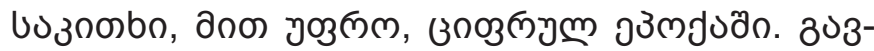

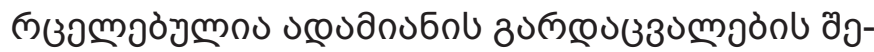

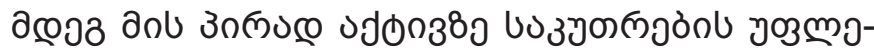

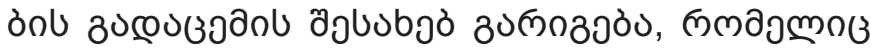

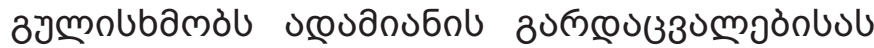

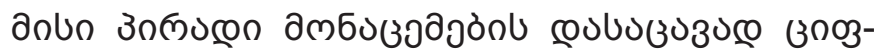

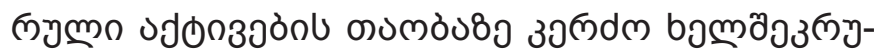

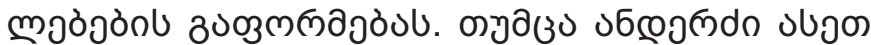

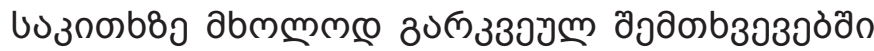

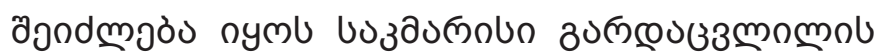

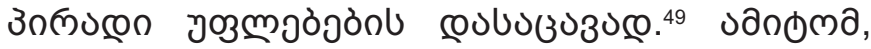

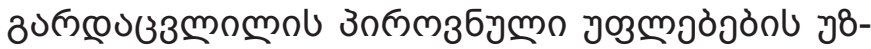

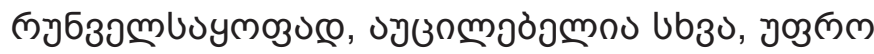

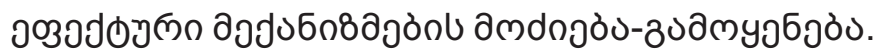

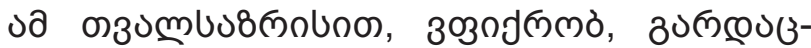

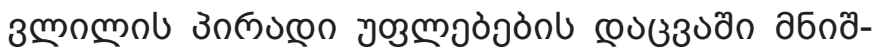

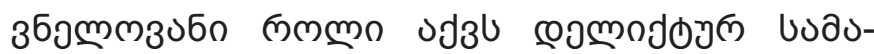

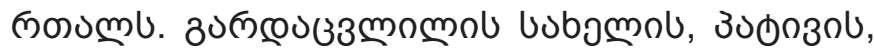

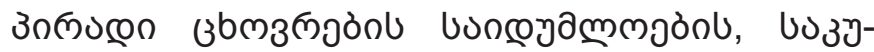

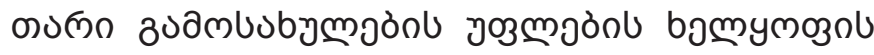

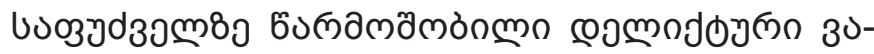

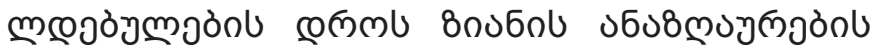

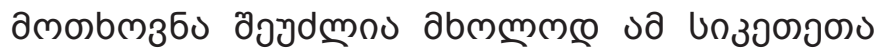

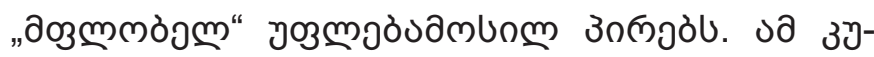

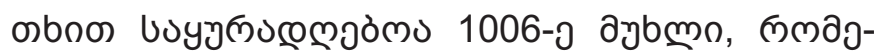

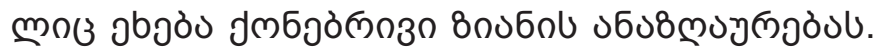

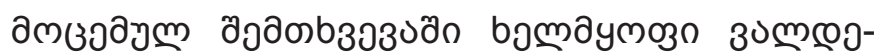

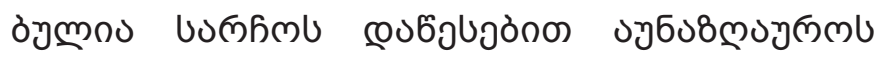

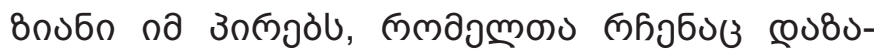

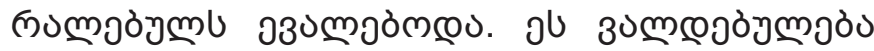

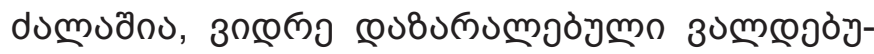

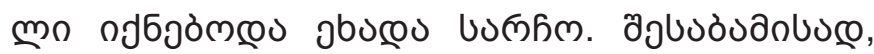

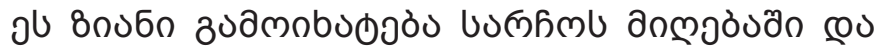

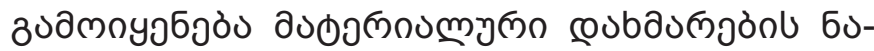

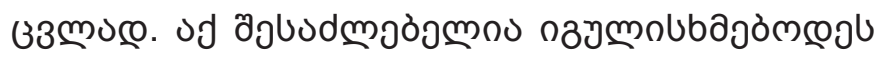

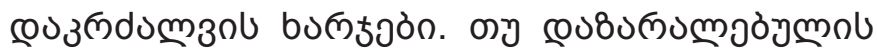

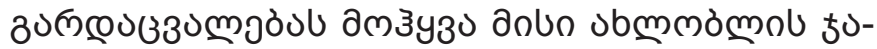

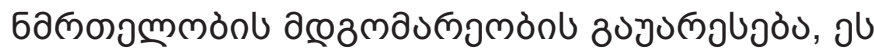

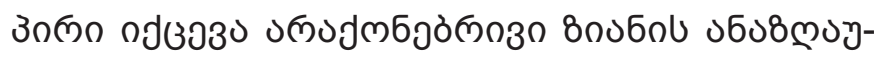

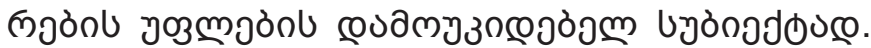

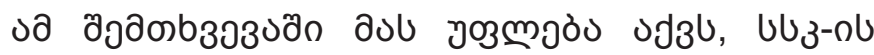

49 Natalie M. Banta. 2016. Death and Privacy in the Digital Age, North Carolina Law Review, Vol. 94, 927.

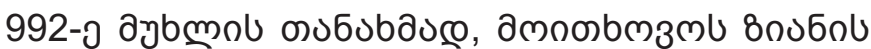

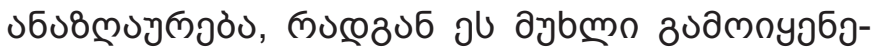

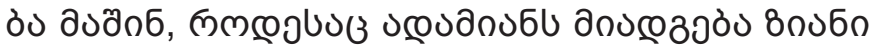

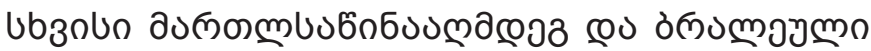

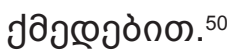

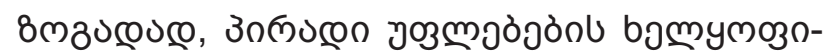

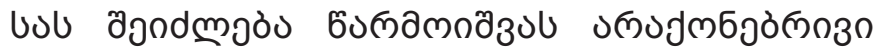

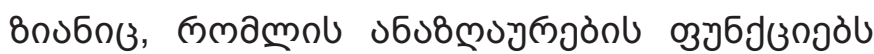

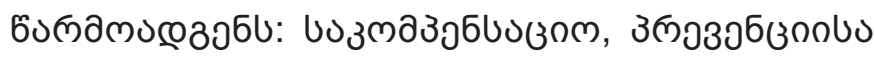

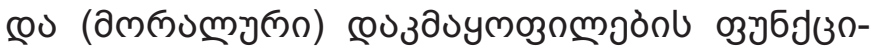

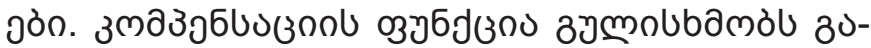

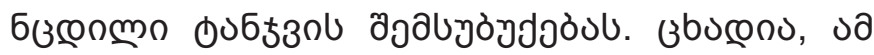

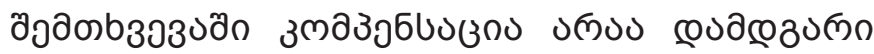

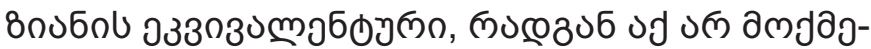

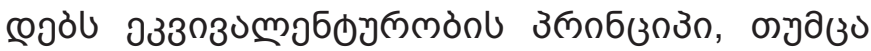

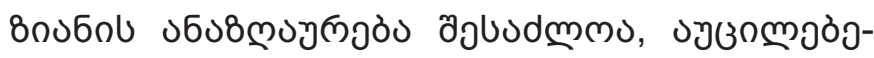

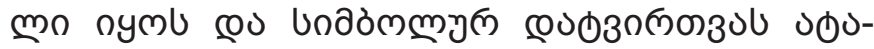

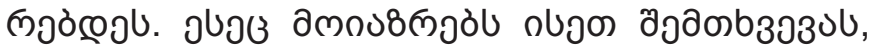

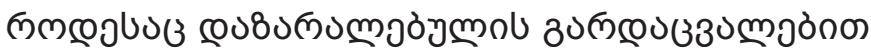
coucozu ubzu ucosanuбou (ubmmómol, алаззо-

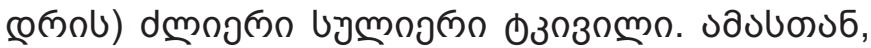

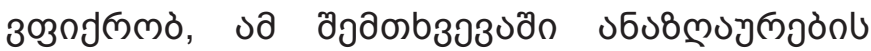

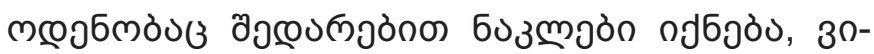

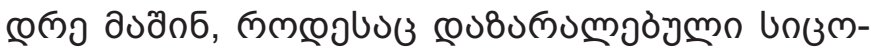

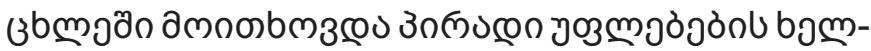

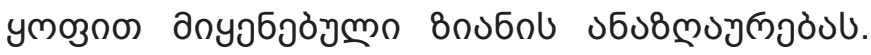

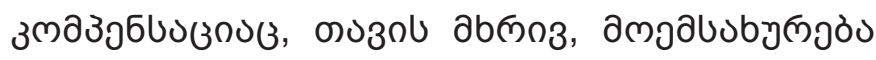

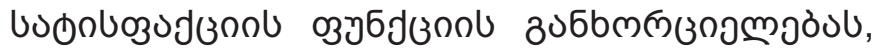

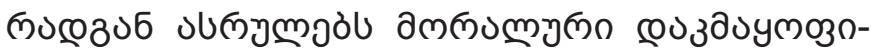

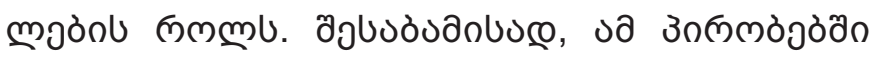

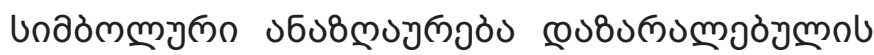

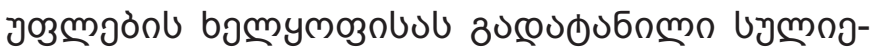

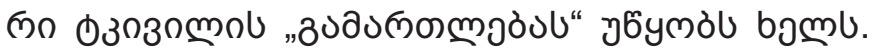

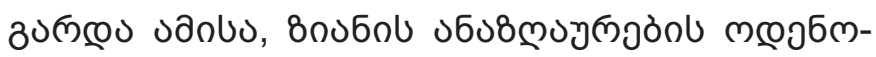

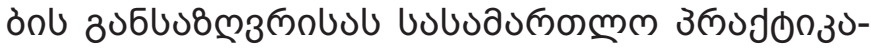

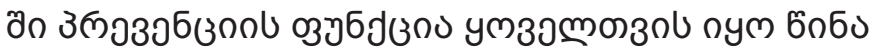

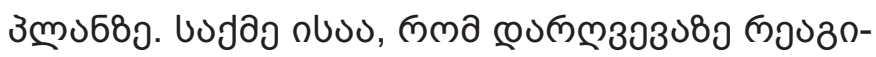

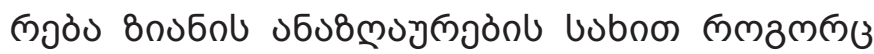

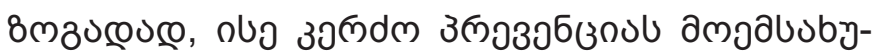
๓оòo. ${ }^{51}$

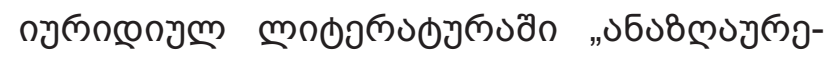

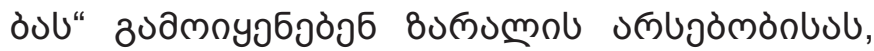

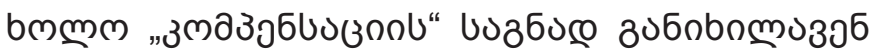

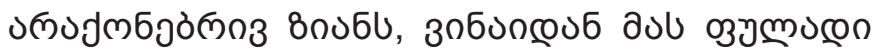

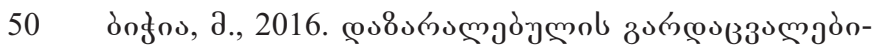

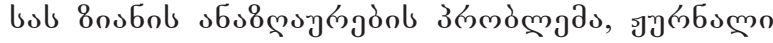

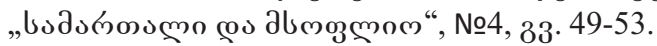

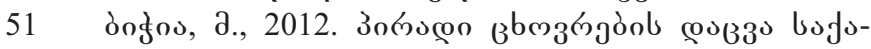

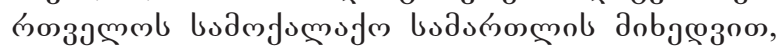
oònģobo, 33. 189-197. 


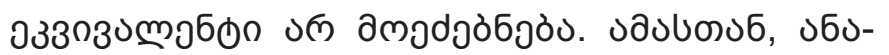

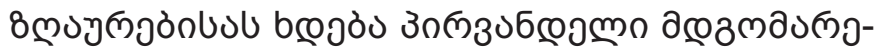

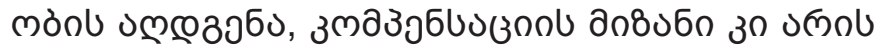

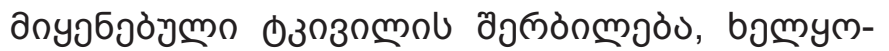

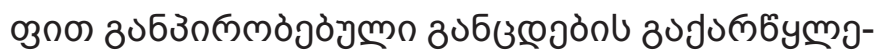

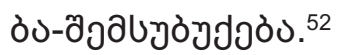

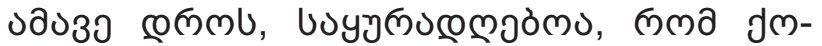

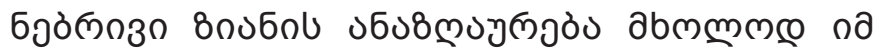

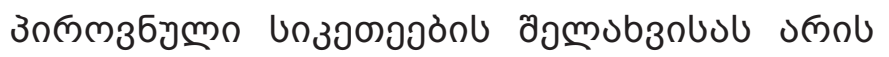

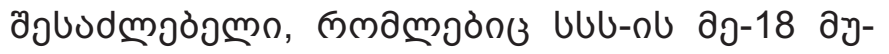

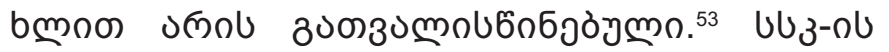

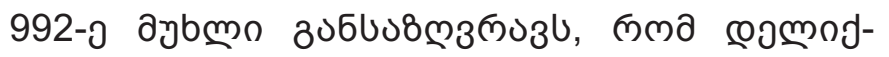

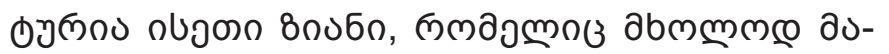

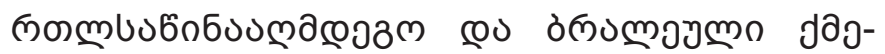

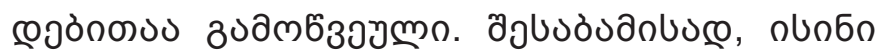

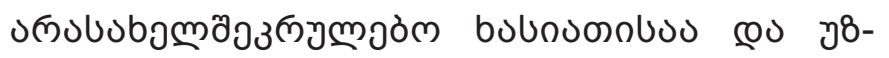

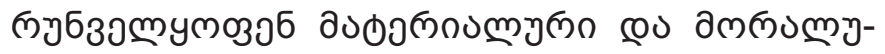

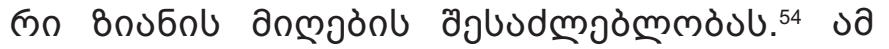

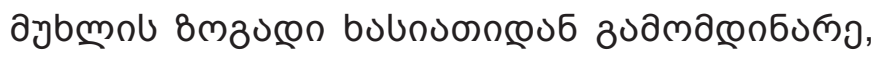

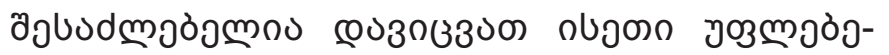

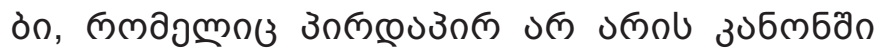

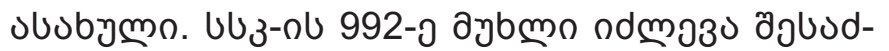

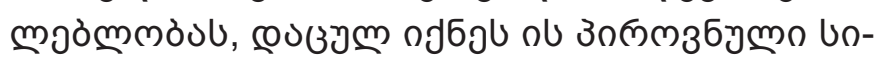

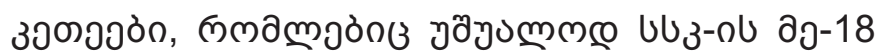

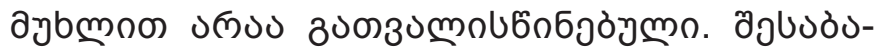

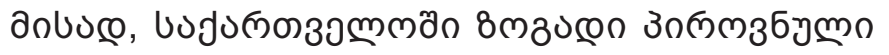

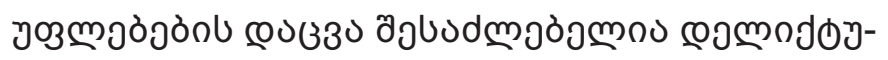

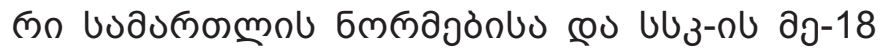

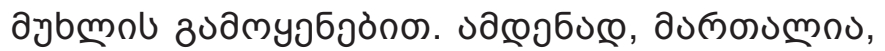

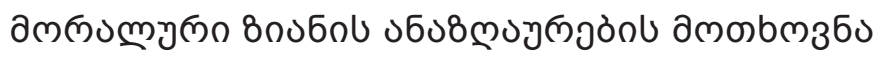

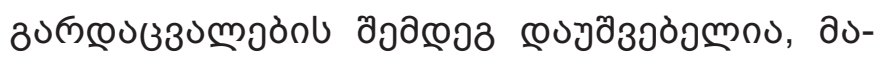

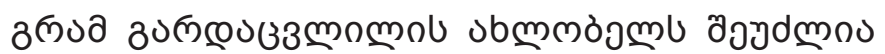

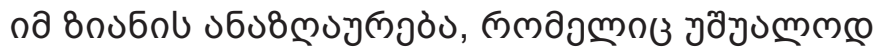

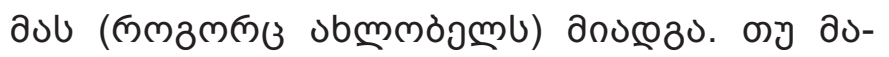

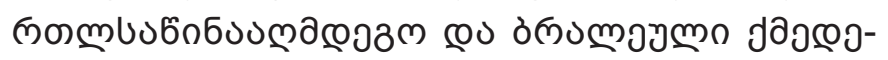

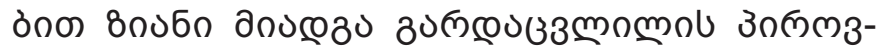

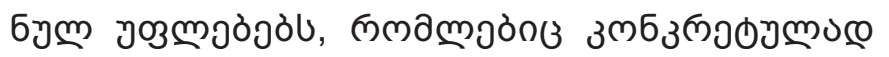

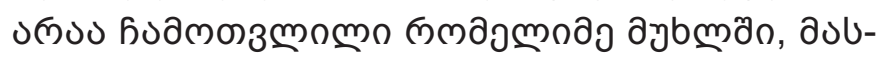

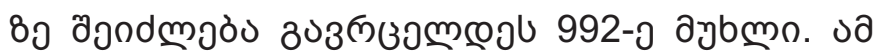

52 Басманова, Н.К., 2008. Сущность и особенности возникновения правоотношений возмещения и компенсации, Автореферат на соискание ученой степени кандидата юридических наук, Иркутск,стр.

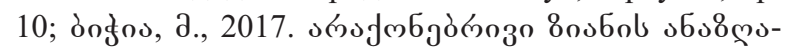

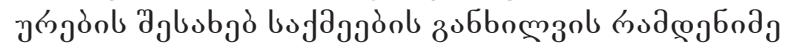

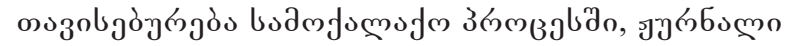

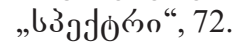

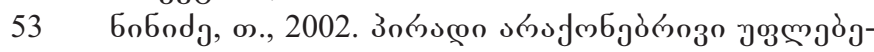

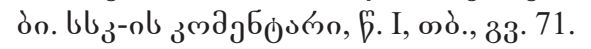

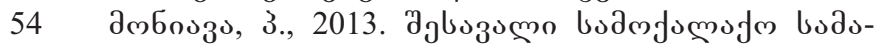

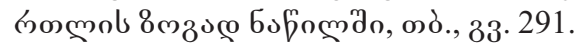

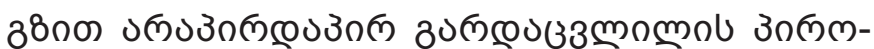

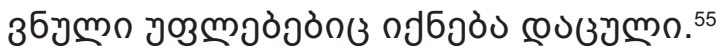

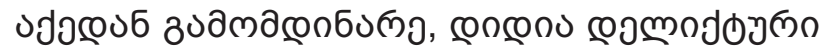

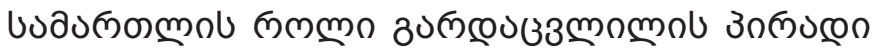

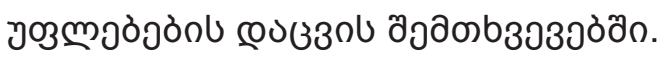

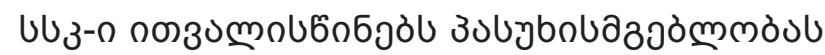

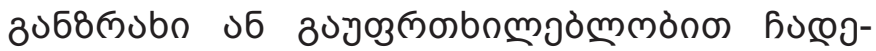

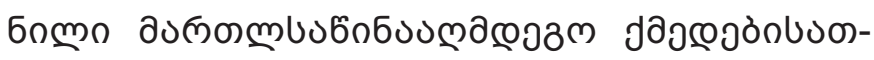

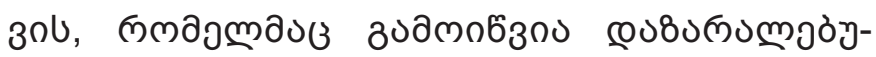

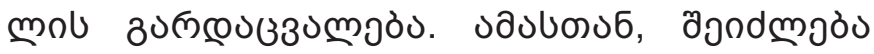
алलкоง

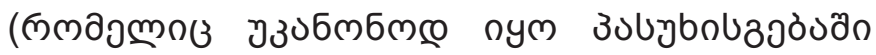

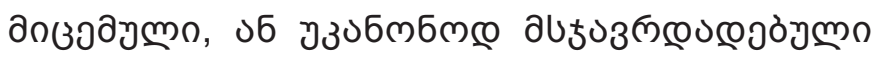

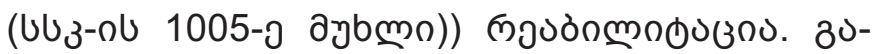

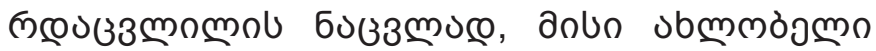

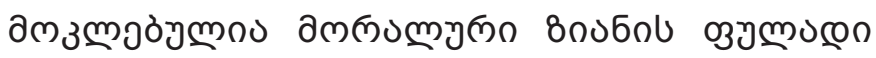

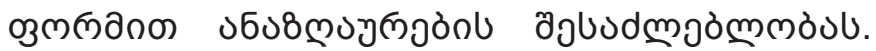

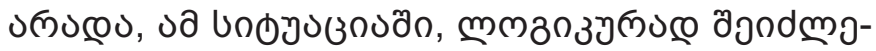

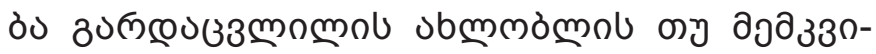

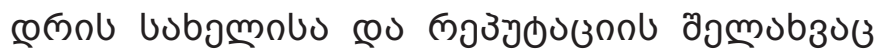

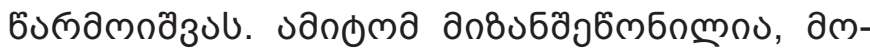

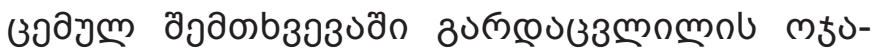

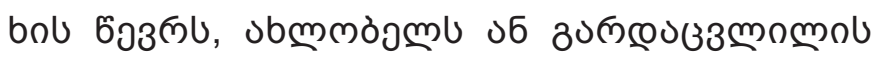

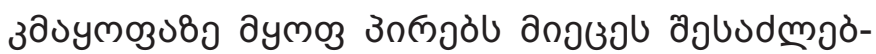

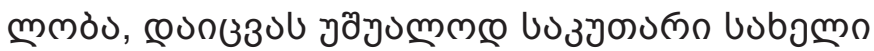

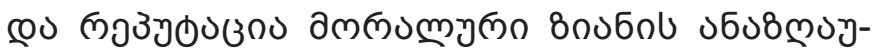

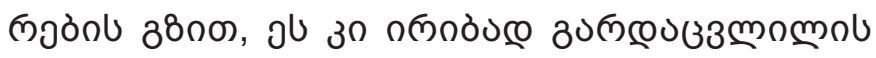

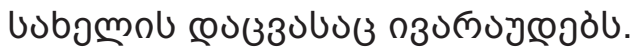

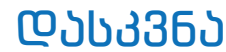

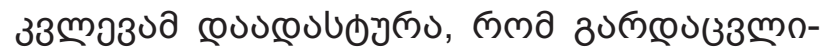

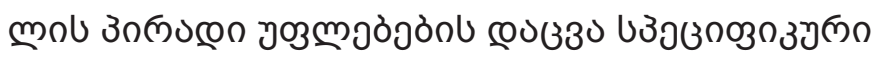

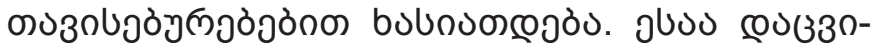

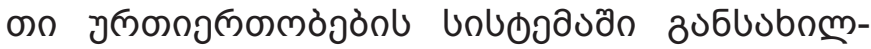

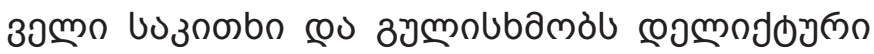

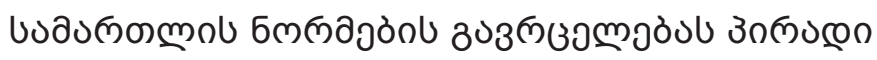

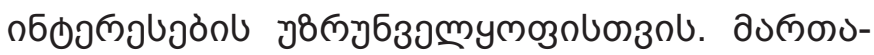

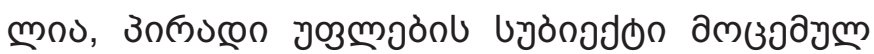

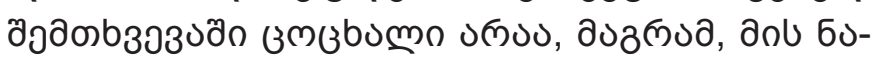

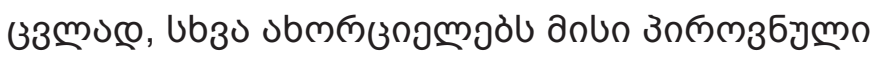

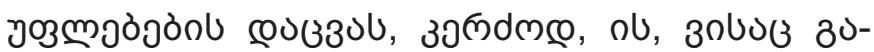
๓ূоง

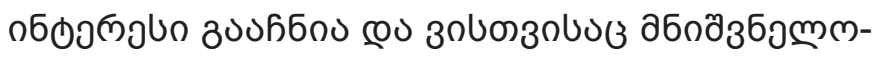

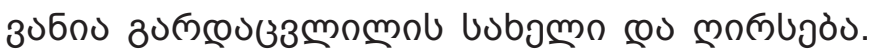

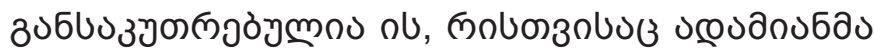

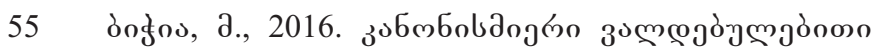

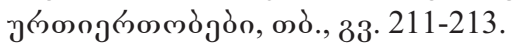




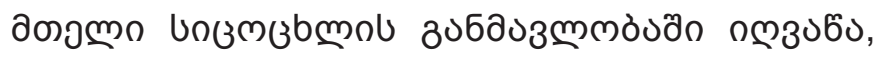

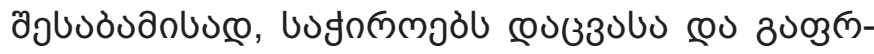
mbngrodul.

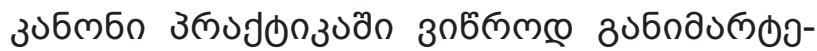

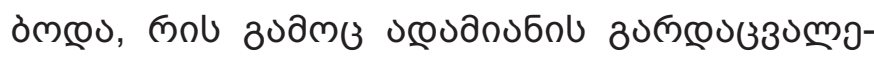

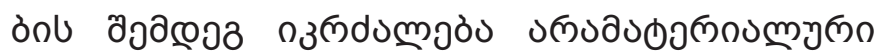

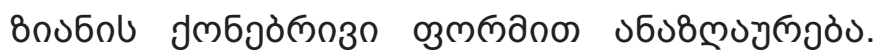

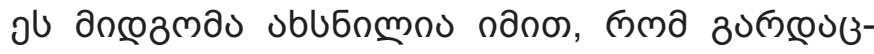

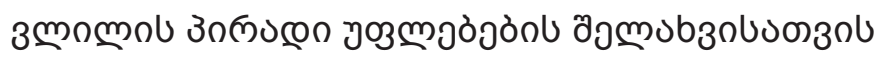

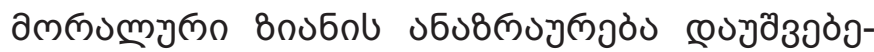

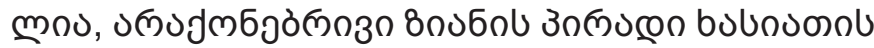

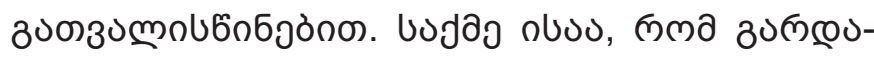

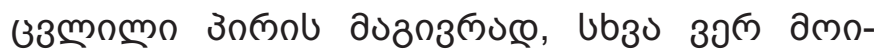

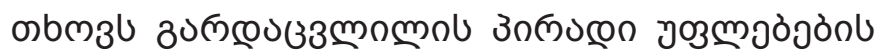

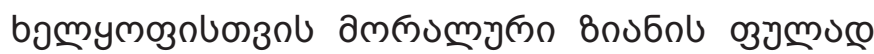

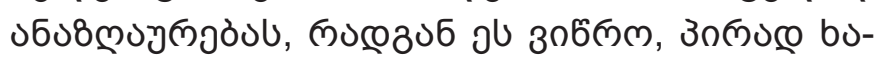

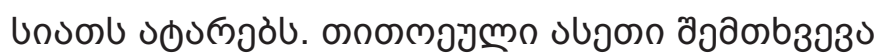

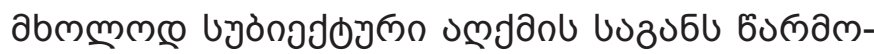

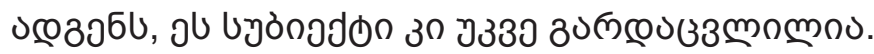

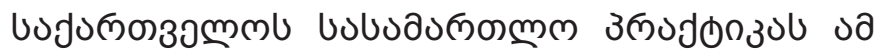

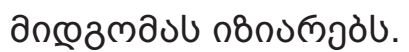

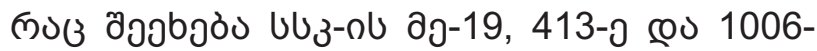

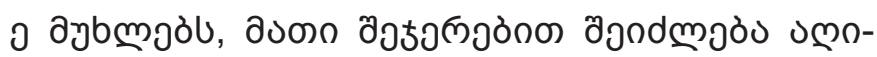

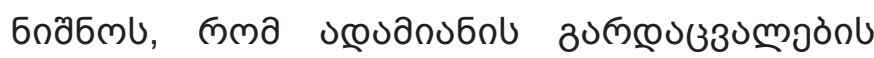

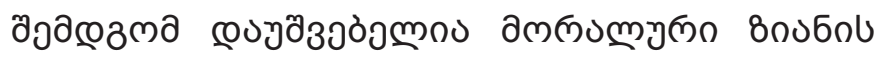

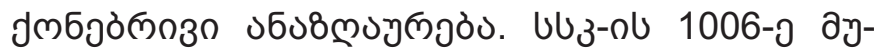

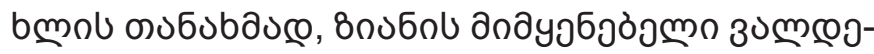

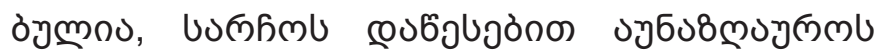

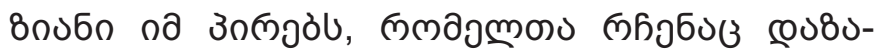

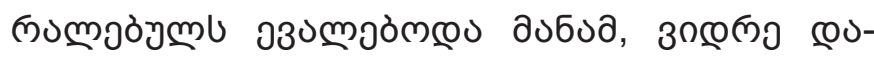

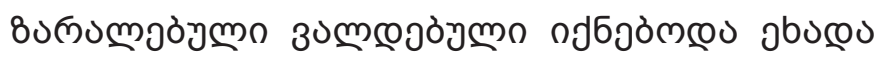

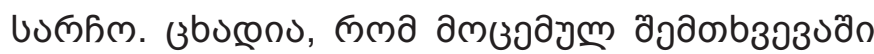

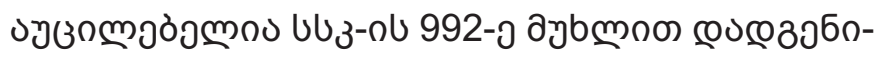

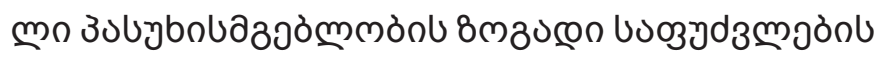

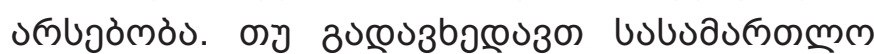

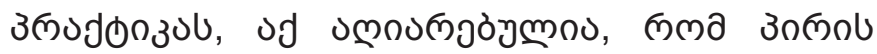

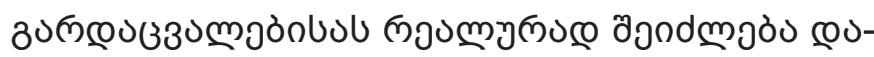

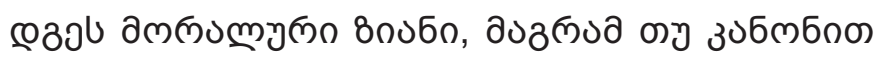

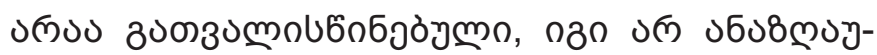
๓ূоว

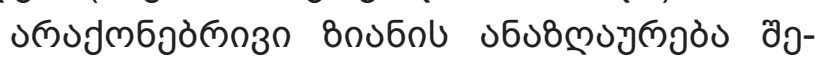

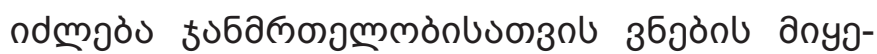

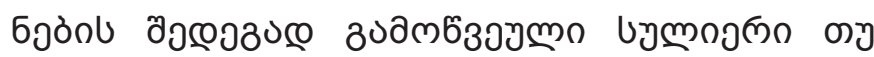

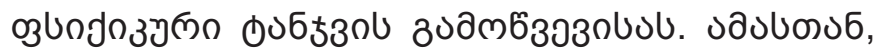

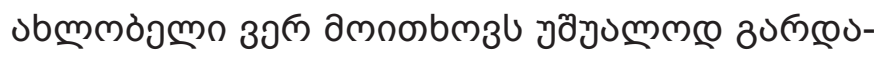

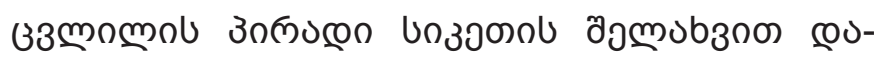

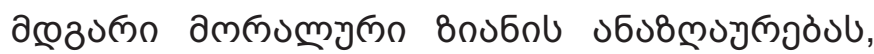

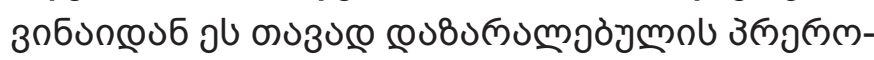

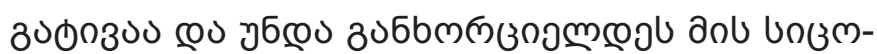

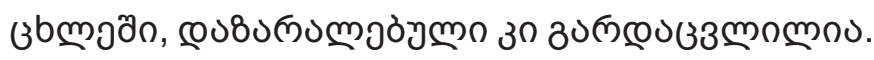

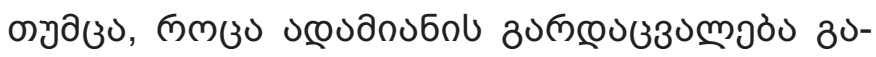

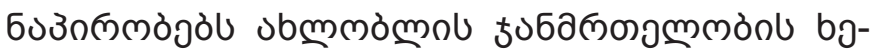

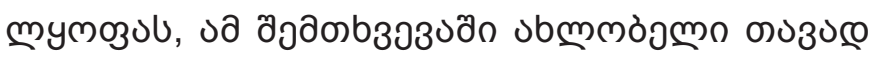

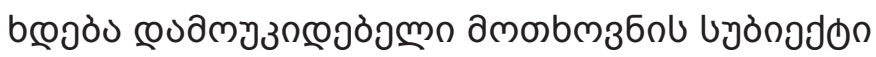

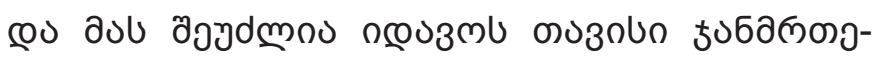

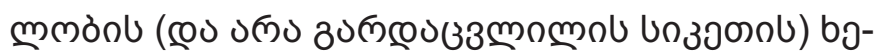

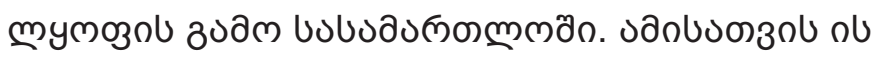

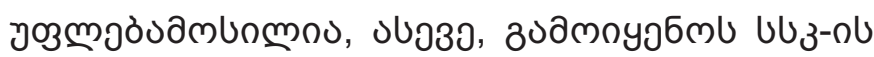

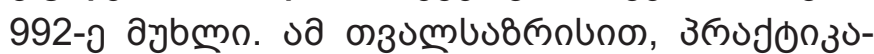

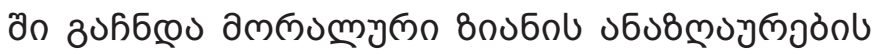

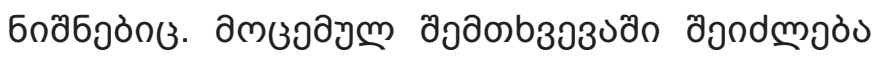

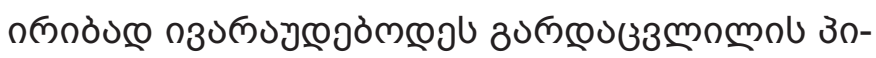

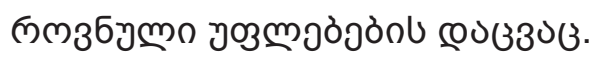

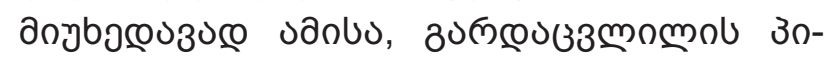

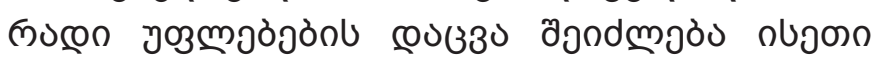

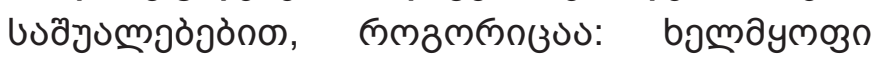

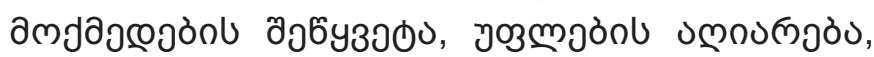

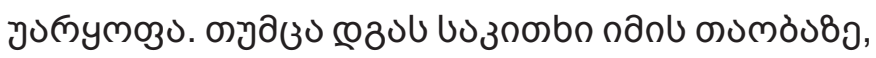

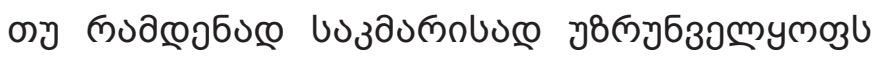

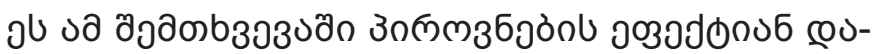

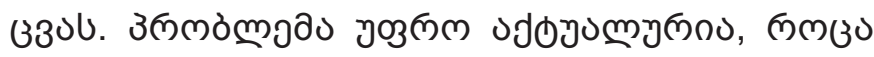

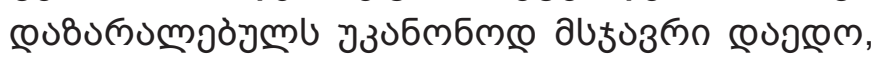

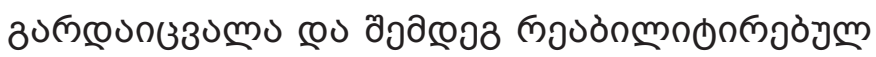

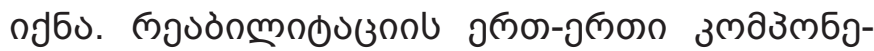

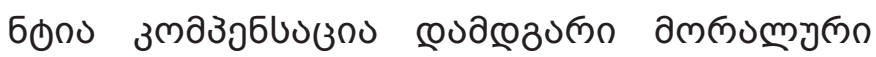

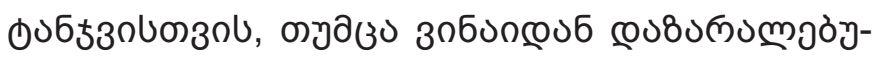

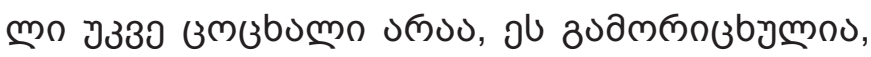

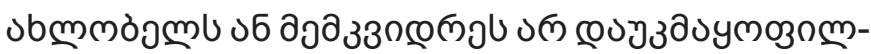

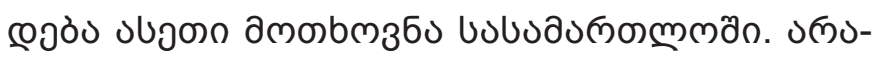

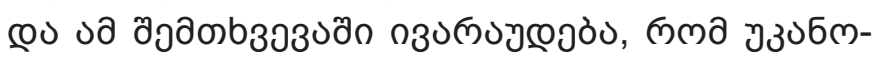

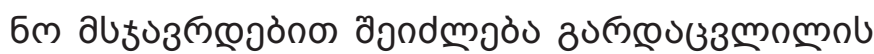

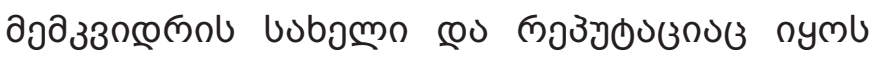

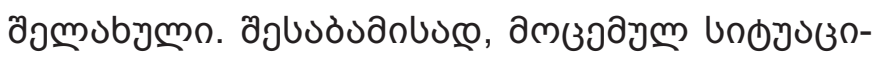

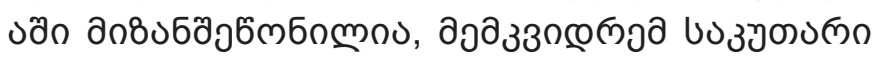

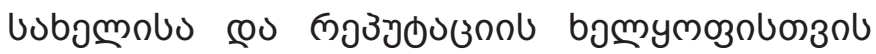

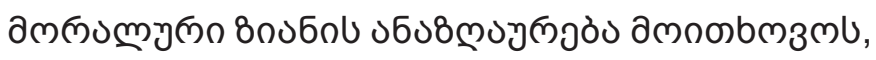

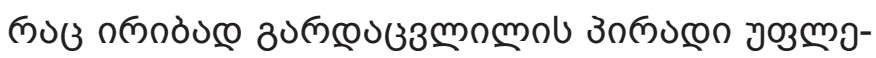

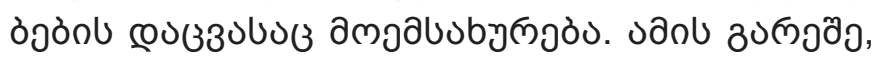

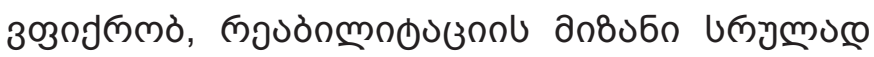

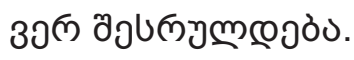




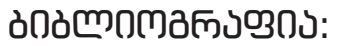

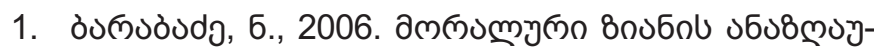

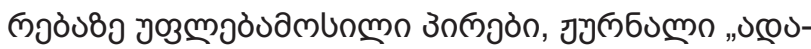

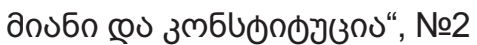

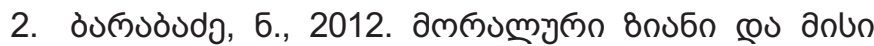

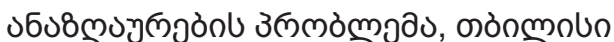

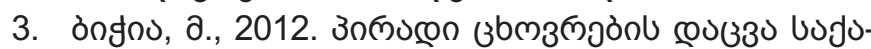

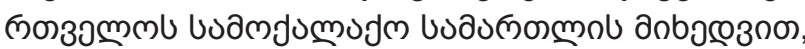
mònmoln

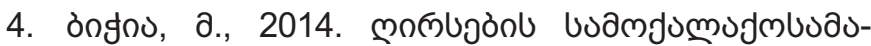

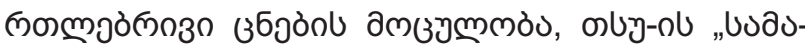

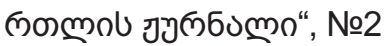

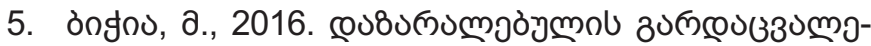

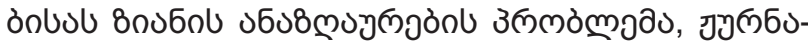

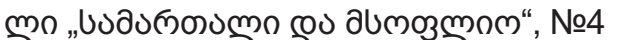

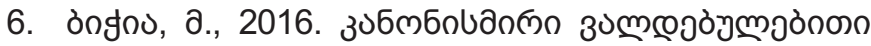

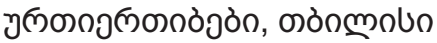

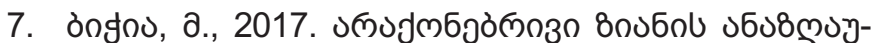

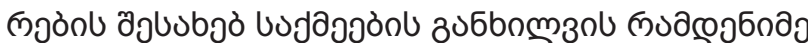

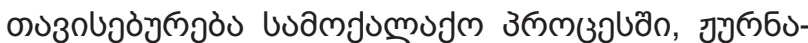

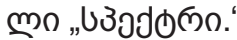

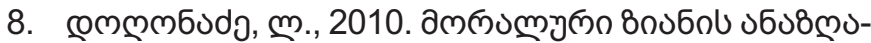

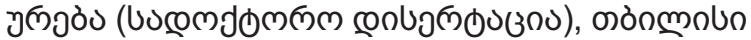

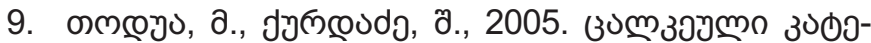

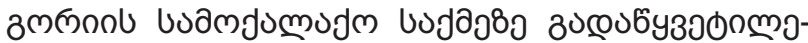

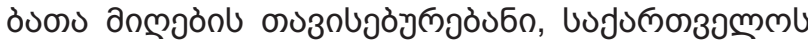

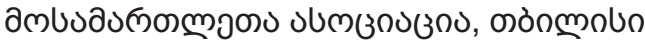

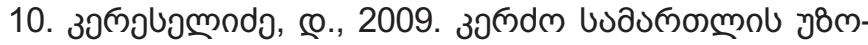

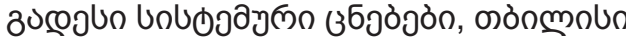

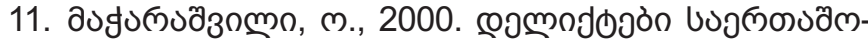

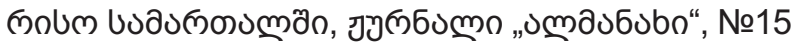

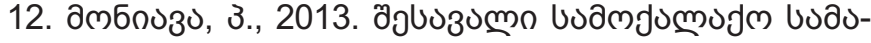

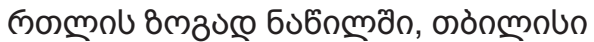

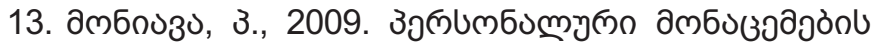

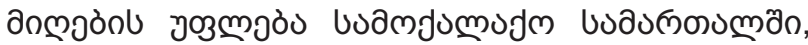

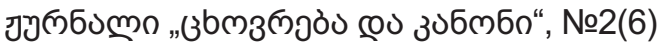

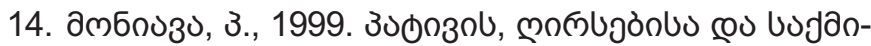

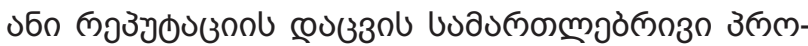

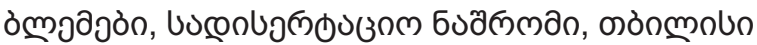

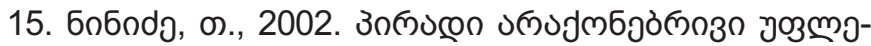

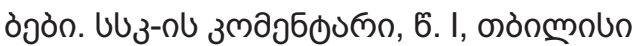

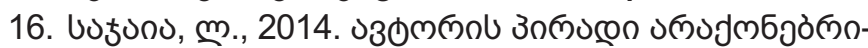

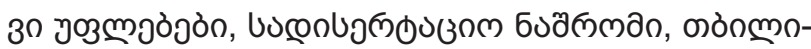
un

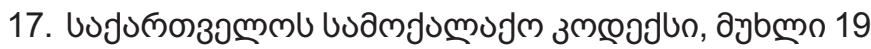

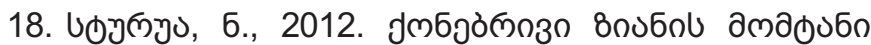

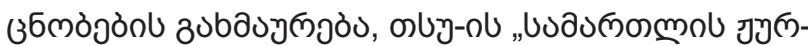
бumo“, №1

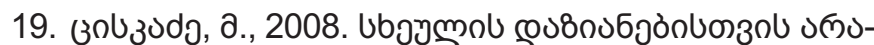

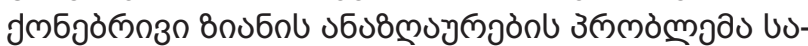

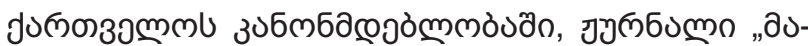

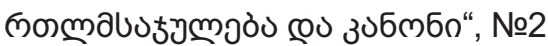

\section{BIBLIOGRAPHY:}

1. Barabadze, N., 2006. Persons entitled to compensation for moral damages, journal of "Human and the constitution", №2

2. Barabadze, N., 2012. Moral damage and the problem of its compensation, Tbilisi

3. Bichia, M., 2012 Protection of personal Life, in accordance with the Civil Law of Georgia, Tbilisi

4. Bichia, M., 2014. Scope of Civil Legal Concept of Dignity (Analysis of Theory and Judicial Practice), TSU Journal of Law, №2

5. Bichia, M., 2016. The problem of Compensating the Damage in Case the Death of Victim Occurs, Law and World, №4

6. Bichia, M., 2016. Legal Obligational Relations, Tbilisi

7. Bichia, M., 2017. Several Features of Civil Procedure about Cases of Compensating Non-property Damages. Journal "Spektri"

8. Dogonadze, L., 2010. Compensation for moral damage (doctoral dissertation), Tbilisi

9. Todua, M., Kurdadze, Sh., 2005. Peculiarities of decision - making ina separate category of civil cases Georgian Judges Association. Tbilisi

10. Kereselidze, D., 2009. General systemic concepts of private law. Tbilisi

11. Moniava, P., 2013. Introduction to the General Part of Civil Law, Tbilisi

12. Moniava, P., 1999. Legal Problems of Protection of Honor, Dignity and Business Reputation, Dissertation, Tbilisi

13. Ninidze, T., 2002. Personal non-property rights. Ssc coment. Book I. Tbilisi

14. Sajaia, L., 2014. Personal non-property rights of the author, dissertation. Tbilisi

15. ChikvaShvili, Sh., 2000. Inheritance law. Tbilisi

16. Jorbenadze, S., 2017. Article 19. Comentary on the civil code of Georgia, the book I. General provisions of the civil code, Tbilisi

17. Civil Code of Georgia, Article 19

18. Macharashvili, O., 2000. Delects in international Law. Journal of Almanac, №15

19. Moniava, P., 2009. The right to receive personal data in civil law, Journal of Life and Law, №2 (6)

20. Sturua, N., 2012. Dissemination of property damage reports, TSU Journal of Law, №1

21. Tsiskadze, M., 2008. The problem of non-pecuniary damage to the body in the legislation of Georgia. Journal of justice law. №2

22. Decision of the chamber of civil Entrepreneurship and control of the supreme court of Georgia, april 24, 2002. (№3k-1218-01) 


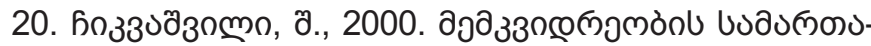
mo, ó̀nmoun

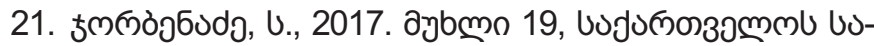

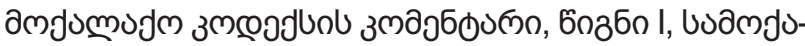

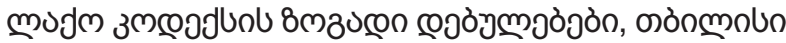

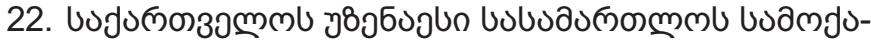

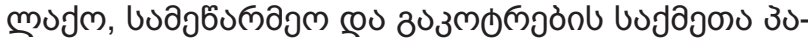

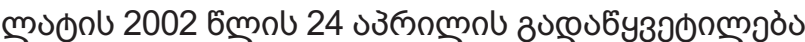
(№33-1218-01)

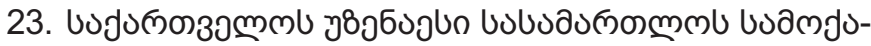

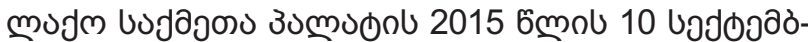

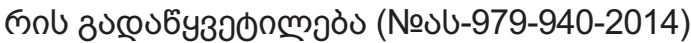

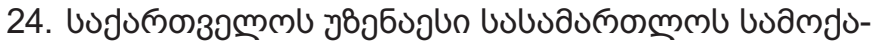

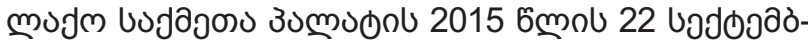

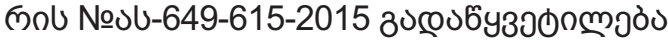

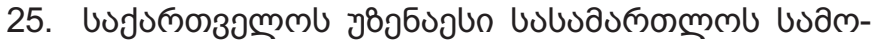

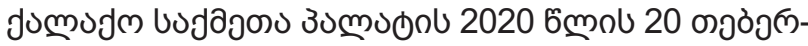

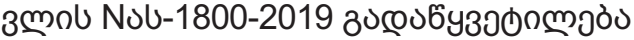

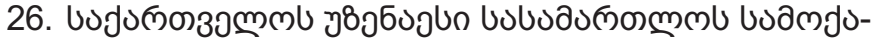

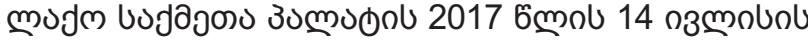

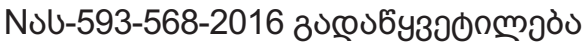

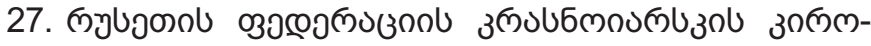

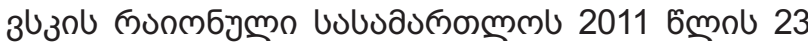

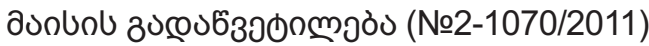

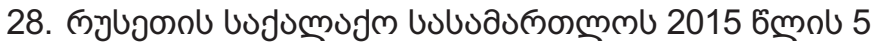

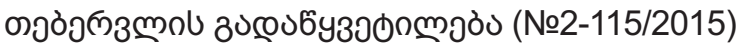

29. Басманова, Н. К., 2008. Сущность и особенности возникновения правоотношений возмещения и компенсации, Авторефрерат на соискание ученой степени кандидата юридических наук, Иркутск

30. Бичия, М., 2016. Основания и объем возмещения вреда понесенного в случае смерти кормильца (ОбзорсудебнойпрактикиГрузии), «Южнокавказский Юридический Журнал», N7

31. Кулешов, Г.В., 2003, Возмещение вреда, причиненного жизни и здоровью военнослужащего, Волгоград

32. Bichia, M., 2016. Analysis of Georgian Judicial Practice on the Grounds and Scope of Compensation of Damages Incurred by the Death of a Breadwinner, South Caucasus Law Journal, N7

33. Chu, N., 2015. Protecting Privacy after Death, 13 Northwestern Journal of Technology and intellectual property, Vol.13, Iss.2

34. Hocks, A., 2012. The Right to Publicity After Death: Postmortem Personality Rights in Washington in the Wake of Experience Hendrix v. HendrixLicensing.com, Seattle University Law Review. Law Review, Vol. 36

35. Natalie M. Banta (2016. Death and Privacy in the Digital Age, North Carolina Law Review. Vol. 94

36. BVerfG, NJW, 1971,S.1645-1647

37. Ciorap v. Moldova, 19/07/2007, ECHR, App. No. 12066/02

38. Gäfgen v. Germany, 01/07/2010, ECHR, App. No 22978/05

39. Case of Sarishvili-Bolkvadze v. Georgia, [19.07.2018], ECHR, App. №58240/08
23. Decision of the civil cases chamber of the supreme court of Georgia, of September 10. 2015 (№as979-940-2014)

24. Decision of the Chamber of Civil Cases of the Supreme Court of Georgia, September 22, 2015 (№as-649-615-2015)

25. Decision of the Chamber of Civil Cases of the Supreme Court of Georgia, February 20, 2020 (№as1800-2019)

26. Decision of the Chamber of Civil Cases of the Supreme Court of Georgia, July 14, 2017 (№as 593-568-2016)

27. Judgment of the Kirovsky District Court of Krasnoyarsk, Russian federation, 2011. 23 May. (№21070/2011)

28. Russian Civil law Judgment, 5 February. 2015. (№ 2-115/2015)

29. Basmanova, N. K., 2008. The essence and features of the emergence of legal relations of reimbursement and compensation, Abstract for the degree of candidate of legal sciences, Irkutsk

30. Bichia, M., 2016. Analysis of Georgian Judicial Practice on the Grounds and Scope of Compensation of Damages Incurred by the Death of a Breadwinner. South Caucasus Law Journal, №7

31. Kuleshov, G.V., 2003, Compensation for harm caused to the life and health of a serviceman, Volgograd

32. Bichia, M., 2016. Analysis of Georgian Judicial Practice on the Grounds and Scope of Compensation of Damages Incurred by the Death of a Breadwinner, South Caucasus Law Journal, N7

33. Chu, N., 2015. Protecting Privacy after Death, 13 Northwestern Journal of Technology and intellectual property, Vol.13, Iss.2

34. Hocks, A., 2012. The Right to Publicity After Death: Postmortem Personality Rights in Washington in the Wake of Experience Hendrix v. HendrixLicensing.com, Seattle University Law Review

35. Natalie M. Banta. 2016. Death and Privacy in the Digital Age, North Carolina Law Review

36. BVerfG, NJW, 1971,S.1645-1647

37. Ciorap v. Moldova, 19/07/2007, ECHR, App. No. $12066 / 02$

38. Gäfgen v. Germany, 01/07/2010, ECHR, App. No 22978/05

39. Case of Sarishvili-Bolkvadze v. Georgia, [19.07.2018], ECHR, App. №58240/08. 
1. Hocks, A., 2012. The Right to Publicity After Death: Postmortem Personality Rights in Washington in the Wake of Experience Hendrix v. HendrixLicensing. com, Seattle University Law Review, Vol. 36, 280. (in English)

2. Barabadze, N., 2012. Moral damage and the problem of its compensation, Tbilisi; Bichia, M., 2012. Protection of personal Life, in accordance with the Civil Law of Georgia, Tbilisi; Moniava, T. (P.). (2013). Introduction to the General Part of Civil Law, Tbilisi, etc. (in Georgian)

3. Ninidze, T., 2002. Article 19 of the Civil Code, in the book: "Commentary on the Civil Code of Georgia", Vol. I, Tbilisi, p. 79. (in Georgian)

4. Bichia, M., 2012. Protection of personal Life, in Accordance with the Civil Law of Georgia, Tbilisi, p. 249-250. (in Georgian)

5. ChikvaShvili, Sh. (2000). Inheritance law. Tbilisi. p. 6. (in Georgian)

6. Bichia, M., 2012. Protection of personal Life in Accordance with the Civil Law of Georgia, Tbilisi, p. 248-249, 259. (in Georgian)

7. Bichia, M., 2016. Legal obligational relations (Handbook), pp. 184-187. (in Georgian)

8. Ciorap v. Moldova, 19/07/2007, ECHR, App. No. 12066/02. (in English)

9. Gäfgen v. Germany, 01/07/2010, ECHR, App. No 22978/05. (in English)

10. Bichia, M., 2014. Scope of Civil Legal Concept of Dignity (Analysis of Theory and Judicial Practice),TSU Journal of Law, №2, pp. 8-10. (in English)

11. Moniava, P., 1999. Legal Problems of Protection of Honor, Dignity and Business Reputation, Dissertation, Tbilisi, p. 34. (in Georgian)

12. Bichia, M., 2012. Protection of personal life, in accordance with the civil law of Georgia, Tbilisi, pp. 159-162. (in Georgian)

13. Moniava, P., 2013. Introduction to the General Part of Civil Law, Tbilisi, pp. 307311. (in Georgian)

14. Moniava, P., 2009. The right to receive personal data in civil law, Journal of Life and Law, №2 (6), p. 16. (in Georgian)

15. Bichia, M., 2016. Legal Obligational relations (Handbook), Tbilisi, pp. 193-194. (in Georgian)

16. Moniava, P., 2013. Introduction to the General Part of Georgian Civil Law, Tbilisi, p. 186. (in Georgian)

17. Sturua, N., 2012. Dissemination of property damage reports, TSU Journal of Law, №1, p. 152. (in Georgian)

18. Bichia, M., 2012. Protection of personal Life, in accordance with the Civil Law of Georgia, Tbilisi, pp. 254-258. (in Georgian)

19. Dogonadze, L., 2010. Compensation for moral damage (doctoral dissertation), Tbilisi, 2010, 174-175, 181. (in Georgian)

20. Decision of the Chamber of Civil Cases of the Supreme Court of Georgia NAS593-568-2016 of July 14, 2017. (in Georgian)

21. Case of Sarishvili-Bolkvadze v. Georgia, [19.07.2018], ECHR, App. 8258240/08. (in English)

22. Decision of the Chamber of Civil Cases of the Supreme Court of Georgia NAS1800-2019 of February 20, 2020. (in Georgian)

23. Decision of the Chamber of Civil Cases of the Supreme Court of Georgia, September 22, 2015 (N-as-649-615-2015). (in Georgian)

24. Barabadze, N., 2012. Moral damage and the problem of its compensation, Tbilisi, pp. 101-103. (in Georgian)

25. Moniava, P., 2013. Introduction to the General Part of Civil Law, Tbilisi, p. 307311. (in Georgian)

26. Jorbenadze, S., 2017. Article 19. Comentary on the civil code of Georgia, the book I. General provisions of the civil code, Tbilisi, p. 157. (in Georgian) 
27. Barabadze, N., 2006. Persons entitled to compensation for moral damages journal of people and the constitution, №22, p. 101. (in Georgian)

28. Civil Code of Georgia, Article 19. (in Georgian)

29. Sajaia, L., 2014. Personal non-property rights of the author, dissertation. Tbilisi, p. 109. (in Georgian)

30. Chu, N., 2015. Protecting Privacy after Death, 13 Northwestern Journal of Technology and intellectual property, Vol.13, Iss.2, p. 255. (in English)

31. Decision of the chamber of civil Entrepreneurship and control of the supreme court of Georgia, april 24, 2002. (№3k-1218-01). (in Georgian)

32. Todua, M., Kurdadze, Sh., 2005. Peculiarities of decision-making in a separate category of civil cases, Georgian Judges Association, Tbilisi. pp. 46-47. (in Georgian)

33. Bichia, M., 2012. Protection of personal Life, in accordance with the Civil Law of Georgia, Tbilisi, pp. 230-233. (in Georgian)

34. Ibid, pp. 197, 199, 227-229. (in Georgian)

35. Russian Civil law Judgment, 5 February. 2015. (№ 2-115/2015). (in Russian)

36. Kuleshov, G.V., 2003, Compensation for harm caused to the life and health of a serviceman, Volgograd, pp. 124-129. (in Russian)

37. Judgment of the Kirovsky District Court of Krasnoyarsk, Russian federation, 2011. 23 May. (№2-1070/2011). (in Russian)

38. Kereselidze, D., 2009. General systemic concepts of private law. Tbilisi. p. 159. (in Georgian)

39. BVerfG, NJW, 1971, S. 1645-1647. (in German)

40. Tsiskadze, M., 2008. The problem of non-pecuniary damage to the body in the legislation of Georgia. Journal of justice law. №2. P. 17. (in Georgian)

41. Macharashvili, O., 2000. Delects in international Law. Journal of Almanac, №15. p. 20-22. (in Georgian)

42. Бичия, М., 2016,. Основания и объем возмещения вреда понесенного в случае смерти кормильца (Обзор судебной практики Грузии). «Южнокавказский Юридический Журнал», N7, стр. 130. (in Russian)

43. Kereselidze, D., 2009. General systemic concepts of private law. Tbilisi. pp. 159160. (in Georgian)

44. Decision of the chamber of Civil Enterepren ceurship and control of the supreme court of Georgia, 2002. 24 April. (№33-1218-01). (in Georgian)

45. Bichia, M., 2016. The problem of compensating the Damage in Case the death of Victim Occurs, Law and World, №4, pp. 51-52. (in Georgian)

46. Jorbenadze, S., 2017. Article 19. Comentary on the civil code of Georgia, the book I. General provisions of the civil code, Tbilisi, p. 158. (in Georgian)

47. Decision of the civil cases chamber of the supreme court of Georgia, of September 10. 2015. (in Georgian)

48. Bichia, M., 2016. Analysis of Georgian Judicial Practice on the Grounds and Scope of Compensation of Damages Incurred by the Death of a Breadwinner. South Caucasus Law Journal, №7, pp. 283-284. (in English)

49. Natalie M. Banta. 2016. Death and Privacy in the Digital Age, North Carolina Law Review, Vol. 94, 927. (in English)

50. Bichia, M., 2016. The problem of compensating the Damage in Case the death of Victim Occurs. Law and World, №4, pp. 49-52. (in Georgian)

51. Bichia, M., 2012. Protection of personal Life, in accordance with the Civil Law of Georgia, Tbilisi. pp. 189-197 (in Georgian)

52. Basmanova, N.K., 2008. The essence and features of the emergence of legal relations of reimbursement and compensation, Abstract for the degree of candidate of legal sciences, Irkutsk, p. 10. (in Russian); Bichia, M., 2017. Several Features of Civil Procedure about Cases of Compensating Non-property Damages. Journal "Spektri", p. 72. (in Georgian)

53. Ninidze, T., 2002. Personal non-property rights. Ssc coment. Book I. Tbilisi. p. 71. (in Georgia)

54. Moniava, P., 2013. Introduction to the General part of Civil Law. Tbilisi. p. 291. (in Georgia)

55. Bichia, M., 2016. Legal Obligational Relations, Tbilisi, pp. 193-194. (in Georgian) 